\title{
Perspective of mesenchymal transformation in glioblastoma
}

Yona Kim ${ }^{1}$, Frederick S. Varn², Sung-Hye Park ${ }^{4}$, Byung Woo Yoon ${ }^{5}$, Hye Ran Park ${ }^{6}$, Charles Lee ${ }^{2}$, Roel G. W. Verhaak ${ }^{2,3^{*}+}$ and Sun Ha Paek ${ }^{1 *+}$ (D)

\begin{abstract}
Despite aggressive multimodal treatment, glioblastoma (GBM), a grade IV primary brain tumor, still portends a poor prognosis with a median overall survival of 12-16 months. The complexity of GBM treatment mainly lies in the interand intra-tumoral heterogeneity, which largely contributes to the treatment-refractory and recurrent nature of GBM. By paving the road towards the development of personalized medicine for GBM patients, the cancer genome atlas classification scheme of GBM into distinct transcriptional subtypes has been considered an invaluable approach to overcoming this heterogeneity. Among the identified transcriptional subtypes, the mesenchymal subtype has been found associated with more aggressive, invasive, angiogenic, hypoxic, necrotic, inflammatory, and multitherapyresistant features than other transcriptional subtypes. Accordingly, mesenchymal GBM patients were found to exhibit worse prognosis than other subtypes when patients with high transcriptional heterogeneity were excluded. Furthermore, identification of the master mesenchymal regulators and their downstream signaling pathways has not only increased our understanding of the complex regulatory transcriptional networks of mesenchymal GBM, but also has generated a list of potent inhibitors for clinical trials. Importantly, the mesenchymal transition of GBM has been found to be tightly associated with treatment-induced phenotypic changes in recurrence. Together, these findings indicate that elucidating the governing and plastic transcriptomic natures of mesenchymal GBM is critical in order to develop novel and selective therapeutic strategies that can improve both patient care and clinical outcomes. Thus, the focus of our review will be on the recent advances in the understanding of the transcriptome of mesenchymal GBM and discuss microenvironmental, metabolic, and treatment-related factors as critical components through which the mesenchymal signature may be acquired. We also take into consideration the transcriptomic plasticity of GBM to discuss the future perspectives in employing selective therapeutic strategies against mesenchymal GBM.
\end{abstract}

Keywords: Glioblastoma, Mesenchymal transition, Master transcriptional regulator, Transcriptomic plasticity, TAMs

*Correspondence: Roel.Verhaak@jax.org; paeksh@snu.ac.kr

† SunHa Paek and RoelG.W. Verhaak: Joint senior authors

${ }^{1}$ Department of Neurosurgery, Cancer Research Institute and Ischemic/

Hypoxic Disease Institute, Seoul National University College of Medicine, Seoul 03080, Korea

${ }^{2}$ The Jackson Laboratory for Genomic Medicine, Farmington, CT 06032, USA

Full list of author information is available at the end of the article

\section{Introduction}

Glioblastoma (GBM) is the most aggressive and infiltrative primary brain tumor in adults. The current standard treatment regimen for patients with newly diagnosed GBM was established in 2005, and consists of maximal safe surgical resection followed by concurrent chemoradiation with temozolomide (TMZ), an FDA-approved alkylating agent [145]. Despite this treatment, the 5-year recurrence rate of GBM after initial treatment is as high as $90 \%[5,163]$. Managing recurrent GBMs is a challenging problem because subsequent treatment options are the original author(s) and the source, provide a link to the Creative Commons licence, and indicate if changes were made. The images or other third party material in this article are included in the article's Creative Commons licence, unless indicated otherwise in a credit line to the material. If material is not included in the article's Creative Commons licence and your intended use is not permitted by statutory regulation or exceeds the permitted use, you will need to obtain permission directly from the copyright holder. To view a copy of this licence, visit http://creativecommons.org/licenses/by/4.0/. The Creative Commons Public Domain Dedication waiver (http://creativeco mmons.org/publicdomain/zero/1.0/) applies to the data made available in this article, unless otherwise stated in a credit line to the data. 
limited and recurrent tumors often manifest in a more aggressive and infiltrative pattern. Thus, the development of effective and new treatment modalities for both newly diagnosed and recurrent GBMs is of exceptional importance [145].

Particularly, in response to growing interest of the personalized medicine for cancer patients, there have been many studies that divided and characterized the molecular background of GBM based on its clinical, genomic, transcriptomic, epigenomic and proteomic features. An attempt to transcriptionally categorize GBM tumors was made by Phillips et al. who identified and characterized three signatures of GBM, known as the proliferative, proneural, and mesenchymal signatures, based on gene expression profiling and subsequent longitudinal analysis of glioma cases [114]. In 2010, a group of researchers from TCGA built upon this work to identify four transcriptomic subtypes of GBM-proneural, neural, classical and mesenchymal-based on unsupervised transcriptomic analysis of 202 newly diagnosed GBM cases, which showed strong associations with genomic alterations of genes such as TP53, EGFR and NF1 [155]. At this point, GBM tumors harboring the mesenchymal signature have gained much attention due to their highly aggressive natures compared to those with other transcriptomic signatures [10, 35, 89, 181, 186]. Notably, mesenchymal GBM was found to be characterized by an increased presence of immune cells, as compared to other transcriptional subtypes [62], questioning whether mesenchymal transcriptional signature is intrinsically captured in GBM cells or a byproduct of bulk RNAsequencing being contaminated by non-neoplastic cells. Wang et al. through tumor cell-intrinsic gene expression analysis, have revealed that the TCGA-derived IDH wildtype GBM transcriptomic signatures can be reduced to the proneural, classical and mesenchymal subtypes, with the neural subtype representing normal cell contamination [161]. Furthermore, other studies using single-cell RNA-sequencing have revealed that some glioma cells themselves exhibit mesenchymal signature, suggesting that this signature is far from being simply tissue artifact $[26,177]$.

Although mesenchymal GBM was initially considered as the most aggressive transcriptomic signature in GBM [16], the significant survival difference was observed only when restricting the samples with low transcriptional heterogeneity, questioning the studies on the transcriptional subtypes of GBM performed without considering transcriptional heterogeneity [161]. However, the wealth of studies performed on so-called "mesenchymal" phenotypes described in the present review and also other reviews collectively suggest that mesenchymal GBM exhibits relatively more aggressive characteristics compared to other transcriptional signatures $[4,9,38]$. Other classification systems of GBM have also been reported based on other parameters (e.g., DNA methylation patterns) and shown to correlate with patient prognosis and also transcriptomic signatures $[66,81,185]$. Although these classification systems may be more robust, we will not further discuss here as the focus of the present review is on the mesenchymal signature of GBM identified through transcriptomic analysis.

Generally, two types of mesenchymal GBM have been described: microenvironment-driven and microenvironment-independent mesenchymal GBM [100, 161]. Non-neoplastic cells of microenvironmental components, especially brain-resident microglia and infiltrated monocyte-derived macrophages, have been shown closely associated with the development of mesenchymal GBM $[11,35,48,130,131]$. Bhat et al. reported that the mesenchymal signature is lost in patient-derived glioma sphere cultures and xenograft models despite originating from mesenchymal tumors, suggesting the necessity of human tumor microenvironmental factors in acquiring and maintaining the mesenchymal phenotypic state of GBMs [11]. Furthermore, the global and regulatory transcriptional profile of tumor-associated macrophages that drive mesenchymal phenotype in GBM has recently been identified, further highlighting the association between microenvironmental components and mesenchymal GBM [131]. On the other hand, mesenchymal transformation has also been reported to occur in a glioma cell-intrinsic manner $[11,47]$. It was shown that the mesenchymal phenotype of initiating GBM was maintained in derived sphere cultures and also as xenograft models, indicating that some glioma cells are capable of sustaining the mesenchymal state independently of their microenvironment [11]. Moreover, it was reported that tumor bulk cells themselves may undergo a subtype transition to mesenchymal signature under a selective pressure of treatment, and this phenomenon was not associated with stromal enrichment via a high rate of cell death in the tumor bulk [47]. Whether microenvironment-driven or -independent, the acquisition of mesenchymal signature poses a significant clinical challenge as it exemplifies the plasticity of GBM and underlies the real problem of treatment resistance [10, 11, 24, 93, 116]. Therefore, understanding the impact of cell-intrinsic and -extrinsic cues on the intratumoral variability in GBM is critical to develop and optimize the multimodal therapeutic strategies for GBM patients. In this review, we will discuss the current molecular pathobiology in mesenchymal transformation in GBM, while focusing on the dynamics and molecular factors associated with the mesenchymal transcriptional state and also their clinical implications. 


\section{Clinical challenges of mesenchymal glioblastoma}

The development of mesenchymal GBM has been found tightly associated with that of resistance to therapeutic agents widely applied and clinically tried for GBM patients [11, 77, 115, 133, 135]. The relationship between the mesenchymal signature of GBM and radiotherapy, which is a part of the current standard-of-care for GBM treatment, has intensively been studied [11, 47]. Bhat et al. demonstrated a mechanistic link between radiation resistance and mesenchymal GBM, presenting evidence of therapeutic risk of ionizing radiation for GBM patients. In this study, they proposed a metagene score of the mesenchymal signature, which consists of proteins such as YKL40, SERPINE1, TIMP1 and TGFBI, and showed that GBM patients with higher mesenchymal metagene score are associated with poor response to radiation regardless of IDH1/2 mutational status [11]. Additionally, Holliday et al. utilized a genetically engineered mouse model of proneural glioma and revealed that the mesenchymal transition of tumor occurred within $6 \mathrm{~h}$ upon radiation, suggesting an intrinsic ability of GBM cells to cope with the therapeutic stress [47]. Moreover, radiation-associated mesenchymal differentiation in GBM was found to contribute to resistance to the alkylating agent TMZ as well [70].

It is now evident that tumor-associated macrophages and microglia (TAMs), which account for as many as $30-50 \%$ of the cell populations in the GBM microenvironment, are the critical stromal elements whose bidirectional communications with glioma cells are associated with the aggressiveness of GBM tumor as well as resistance to standard therapies [48, 79]. Recently, Akkari et al. who analyzed the phenotypic heterogeneity and plasticity of distinct TAM populations in the irradiated GBM microenvironment, have shown that the number of TAMs is progressively accumulated throughout the course of the 5-day fractionated radiotherapy regimen in GBM preclinical mouse models [2]. This observation is further supported by the findings of Doan et al. who showed that the global mRNA expression changes following irradiation are associated with a positive regulation of macrophage chemotaxis [31]. These results suggest that radiotherapy may elicit the recruitment of TAMs, which have also been reported to induce mesenchymal differentiation in GBM cells followed by radioresistance [11, 153].

Furthermore, resistance to antiangiogenic therapy, such as bevacizumab, which is a recombinant human monoclonal antibody acting against the vascular endothelial growth factor (VEGF), has been found closely linked to the mesenchymal phenotype of GBM [115]. Sandmann et al. in their retrospective analysis of the AVAglio (Avastin in Glioblastoma) Trial, found that only IDH1 wild-type GBM patients with proneural subtype derived both overall and progression-free survival benefit compared to placebo group [133]. Although GBM patients with mesenchymal subtype experienced longer progression-free survival upon bevacizumab treatment than placebo, their overall survival was not increased, supporting the notion that tumor progression features visible through intra-patient imaging suppressed by antiVEGF treatment are most readily present in mesenchymal GBM.

Aforementioned remarks of mesenchymal GBM present a critical issue of the potential therapeutic risk of both current standard-of-care and novel treatment modalities. However, in order for mesenchymal transition to be established as a key target for GBM adjuvant therapy, additional studies are required to understand the transcriptome-wide architecture of intratumoral variability in GBM.

\section{The transcriptome of mesenchymal glioblastoma}

Our understanding of the transcriptional heterogeneity was extended from intertumoral to intratumoral level when GBM tumors were analyzed at multiple spatial scales and also at single-cell level. Sottoriva et al. by analyzing spatially distinct GBM fragments, demonstrated that different transcriptomic subtypes are displayed within the same tumor [142]. Also, Patel et al. showed that established GBM transcriptional subtype classifiers are variably expressed across individual cells within a tumor. These studies demonstrate that multiple transcriptomic signatures associated with cellular states coexist within a GBM tumor, suggesting that the expression profile of bulk tumors represents the average of highly heterogeneous transcriptional state admixtures of GBM cells [108]. Indeed, intratumoral heterogeneity suggests a critical concern for GBM treatment, as the collapse of tumor cells with a certain phenotype may result in the initiation and proliferation of tumor cells with other phenotypes, which may lead to mesenchymal transformation in GBM. Therefore, understanding the intratumoral transcriptional heterogeneity and how it may affect the course of GBM progression towards the mesenchymal signature is critical.

Many studies have reported the cellular and phenotypic plasticity of GBM transcriptome not only as the main driver of intratumoral heterogeneity, but also a characteristic phenomenon during tumor evolutionary dynamics [158, 161]. In particular, the significance of transcriptomic subtype transitions between diagnosis and recurrence and in response to radio/chemotherapy has increasingly been recognized due to their contribution to the development of mesenchymal-related characteristics $[38,98,104,114,135]$. In the following sections, 
we will highlight some of the important findings regarding the transcriptome of mesenchymal GBM in relation to its transcriptional network, master transcriptional regulators, and the signaling pathways and factors that are hijacked by GBM to acquire the mesenchymal phenotype.

\section{The transcriptional network of mesenchymal glioblastoma} In response to increasing knowledge of the molecular characteristics of GBM, Carro et al. have drawn the first comprehensive map of the transcriptional network of mesenchymal signature of GBM through reverse-engineering and an unbiased microarray technique [16]. In this work, the authors utilized context-specific regulatory network models and identified mesenchymal gene expression signature, which generally consisted of several transcriptional factors and their regulons. Importantly, the transcriptional network of mesenchymal GBM was found to be closely intertwined with Nuclear Factor- $\mathrm{kB}$ (NF-kB) signaling pathway $[11,169]$. NF- $\mathrm{kB}$ is a ubiquitous transcription factor known to play a crucial role in aggressive mesenchymal differentiation in virtually all types of malignancies, including GBM [72, 148]. Generally, NF- $\mathrm{kB}$ is activated by a variety of both cell-extrinsic (e.g., microenvironmental factors) and -intrinsic (e.g., genomic aberrations) factors and subsequently conducts an orchestra of transcription factors and co-regulating partners, such as STAT3 and HIF- $1 \alpha$, to potentiate mesenchymal program $[37,59]$. In particular, NF- $\kappa B$ has been shown to directly induce the expression of mesenchymal proteins (e.g., CD44, N-cadherin, Vimentin) and regulate the expression of key molecules that promote inflammatory microenvironment (e.g., TNF $\alpha$, CCL2, IL-6) [28, 32, 90].

One of the crucial findings from analyzing the transcriptional network of mesenchymal GBM is the identification of master transcriptional regulators, which are critical in inducing and sustaining the mesenchymal properties of GBM [9]. The molecular and clinical aspects of these master transcriptional regulators are discussed next.

\section{Master transcriptional regulators of mesenchymal glioblastoma}

Cancer-associated master transcriptional regulators are proteins that govern and regulate transcriptional cellular state of tumor and may thus be associated with potential therapeutic vulnerabilities [139]. In many types of cancer, it has been shown that genetically and/or pharmacologically inhibiting a master transcriptional regulator and its downstream signaling pathways may be a promising therapeutic strategy [3,12, 117, 124, 128]. An attempt to identify master regulators of mesenchymal GBM was first initiated by Carro et al. who suggested STAT3 and
$\mathrm{C} / \mathrm{EBPb}$ as synergistic master transcriptional regulators for mesenchymal GBM [16]. Their co-expression was associated with reprogramming of neural stem cells into an aberrant mesenchymal lineage, while their downregulation resulted in the collapse of the mesenchymal signature and reduced aggressiveness of the tumor. Interestingly, the concurrent and synergistic activity of STAT3 and C/EBPb as master mesenchymal regulators seemed to oppose their normal biological roles-astrocytic differentiation and neurogenesis, respectively-in the developing nervous system $[99,105]$. The authors hypothesized that GBM cells have an ability to tolerate such an "abnormal" situation by activating downstream signaling pathways leading to an aberrant mesenchymal transformation. In addition, although sitting at a less hierarchical position in the regulatory network of the mesenchymal transcriptome than STAT3 and C/EBPb, FOSL2 and RUNX1 were also identified as potential master regulators for mesenchymal transformation in GBM [16]. Interestingly, epigenetic changes on the promoterassociated methylation sites of these two master regulators were found to be associated with mesenchymal transition accompanied by multitherapy resistance [135].

Another master regulator was found to be transcriptional coactivator with PDZ-binding motif (TAZ), whose up-regulation triggered the expression of mesenchymalrelated proteins and aberrant osteoblastic and chondrocytic differentiation in proneural glioma stem cells in a transcriptional enhanced associate domain (TEAD)dependent fashion. Interestingly, inferred downstream targets of TAZ largely did not overlap with those of STAT3 and C/EBPb. Such result suggests that TAZ may be an independent modulator of the mesenchymal signature and that multiple routes leading to the mesenchymal phenotype in GBM exist [10]. More recently, hyperactivation of TAZ was found to be associated with mesenchymal transition and tumor necrosis in GBM [173]. Of note, TAZ, and its paralog Yes-associated protein (YAP), participate as downstream transcription coactivators in the Hippo signaling pathway, which is an evolutionarily conserved regulator of tissue growth [50]. Dysregulation of the pathway has been reported to be associated with cancer development and chemoresistance in variety types of cancer, including GBM $[15,180]$. As recently reviewed by Masliantsev et al. activating large tumor suppressor kinase 1/2 (LATS1/2)-dependent inhibitory signals that phosphorylate TAZ/YAP and directly disrupting TAZ/YAP-TEAD-mediated transcription may be effective therapeutic approaches to target the Hippo pathway [88]. The therapeutic potential of the benzoporphyrin derivative verteporfin, an inhibitor of TAZ/YAPTEAD complex, was recently examined and it was shown that verteporfin suppressed expression of TAZ/YAP 
transcriptional targets and induced apoptosis of EGFRamplified/mutant GBM cells [156]. As EGFR amplification is a prominent characteristic in classical subtype of GBM [155], it would be relevant to examine the efficacy of verteporfin in inhibiting mesenchymal transition in GBM by targeting TAZ. Moreover, it was found that NF- $\mathrm{kB}$ controls the expression of these three master transcription factors to potentiate mesenchymal differentiation in proneural glioma sphere cultures, which subsequently exhibit an enrichment of $\mathrm{CD} 44^{+}$subpopulations and radioresistant phenotypes $[11,169]$.

Furthermore, the interplay between microenvironmental factors and the activity of master transcriptional regulators has been implicated. Generally, necrosis and hypoxia are considered as crucial pathobiological features of the neoplastic microenvironment [49]. Interestingly, it has been observed that the expression of master mesenchymal regulators, especially $\mathrm{C} / \mathrm{EBPb}$ and STAT3, is significantly associated with the development of necrotic and hypoxic microenvironment of GBM $[9,25]$. As mentioned previously, macrophages and microglia are the integral components of the tumor microenvironment, creating a supportive stroma for GBM cell expansion and invasion [119]. Although commonly referred to as "TAMs" as a collective term, these are indeed two separate cellular entities with different ontogeny [48], and their ratio has recently been demonstrated to vary depending on the stage of GBM progression [2]. Interestingly, each of these cellular entities has been reported to modulate the activity of the master transcriptional regulator, especially STAT3, suggesting that they have differential, and yet, common roles in promoting mesenchymal transition in GBM. Dumas et al. reported that mTORdependent regulation of STAT3 and NF-kB activity in microglia were induced by GBM-initiating cells, which subsequently promote an immunosuppressive microglial phenotype, and that such mTOR activity is most significantly correlated with tumor-associated microglia signatures in the mesenchymal subgroup of GBM [33]. Moreover, the interaction between GBM-released factors and monocytes, which are the precursor to macrophages, has also been identified to contribute to the immunosuppressive microenvironment of mesenchymal GBM [32]. It has been shown that monocytes preferentially take up GBM-derived exosomes, which traverse the monocyte cytoplasm and mainly release STAT3, thereby triggering up-regulation of programmed death ligand 1 and skewing monocytes toward the immune suppressive M2 phenotype [40].

It is important to note that not all mesenchymal GBMs are regulated by these identified master transcriptional regulators, implying that there are still undiscovered master regulators that may regulate the mesenchymal properties of GBMs working synergistically or even independently of the previously identified master regulators. Intriguingly, studies on the master regulators of mesenchymal GBM raise a critical question as to whether these regulators are the master transcription factors of the mesenchymal state of glioma cells or those of the tumor microenvironmental components or those of both. Nonetheless, identification of additional novel master regulators may provide a clue as to how to evade mesenchymal differentiation-associated therapeutic risk and subsequently aid in the development of effective therapeutic intervention against high-grade glioma.

\section{Transcriptomic plasticity}

It is now a well-established notion that GBM is a dynamic neoplasm whose transcriptome is capable of undergoing transition in response to selective pressure in different biological and pathophysiological settings. Such plasticity accounts for not only a high degree of inter- and intratumoral transcriptional heterogeneity, but also a birth of multitherapy resistant clones upon recurrence and/or in response to treatments.

It has been reported that proneural GBMs may acquire therapeutic resistance and more aggressive, angiogenic and hypoxic potential by shifting their transcriptomic and phenotypic signatures toward mesenchymal GBMs [11, 38, 91]. Such transcriptomic plasticity of GBM upon treatment and/or recurrence is often referred to as a "proneural-to-mesenchymal transition", or PMT [9]. This phenomenon is generally described analogous to epithelial-to-mesenchymal transition (EMT), which is one of the dominant features driving invasiveness and metastasis in carcinomas [144]. An increasing amount of evidence has demonstrated the existence of PMT and suggested that first-line therapy for primary disease may not effectively work for recurrent tumor due to this process $[45,47,70]$. However, recurrent GBMs, especially those that have undergone mesenchymal transformation, have been reported to be associated with an increased presence of TAMs overall $[79,161]$, raising an issue mentioned earlier regarding bulk RNA sequencing. Moreover, although PMT was initially described as a "frequent" event and post-therapeutic characteristic of GBM [114, 166], a longitudinal transcriptome analysis performed by Wang et al. showed that $55 \%$ of tumors from IDHwildtype GBM patients retained their original transcriptional subtype at recurrence and also that the frequency of PMT was not significantly higher than that of other subtype transitions [161].

However, consistent observations that GBM tumors that have undergone mesenchymal transformation are associated with increased aggressiveness and multitherapy resistance highlight the importance of investigating 
the underlying mechanisms and associated therapeutic targets $[161,166]$. Generally, molecular features, intratumoral heterogeneity, immunogenicity, microenvironmental factors, and treatments have been reported to shift GBM transcriptome towards the mesenchymal signature. In the following sections, some of the main mechanisms and factors exploited by GBM to acquire the mesenchymal phenotype are discussed.

\section{Microenvironmental factors}

The extensive heterogeneous milieu of GBM tumors is characterized not only by several distinctive cellular entities, but also by the presence of multiple subclonal populations of GBM cells harboring different cellular states in the same tumor [100]. Importantly, dynamics associated with phenotypic heterogeneity have been reported to be instructed by the tumor microenvironment in a nonhierarchical and reversible manner [30]. Such immense heterogeneity and plasticity of GBM is now considered as a major contributing factor for overcoming selective pressures both during tumor progression and adaptation to therapeutic stresses. The coexistence of subpopulation of GBM cells of multiple transcriptional states and also that of different types of cells in the tumor microenvironment are depicted in Fig. 1 with an emphasis on their roles on promoting the mesenchymal signature.

Transcriptomic plasticity of GBM is significantly influenced by cellular heterogeneity in the tumor microenvironment $[113,134]$. The continuous crosstalk between tumoral and non-tumoral cells is basically viewed as responsible for nearly all events that facilitate the selfsustained growth and invasion of neoplastic cells and therapy-resistance $[159,183]$. An intimate link between the expression of a variety of immune-related genes and mesenchymal GBM reported in many studies has suggested that immunological and inflammatory processes may foster the establishment of the mesenchymal signature $[11,32,130]$. Accordingly, it has been found that the

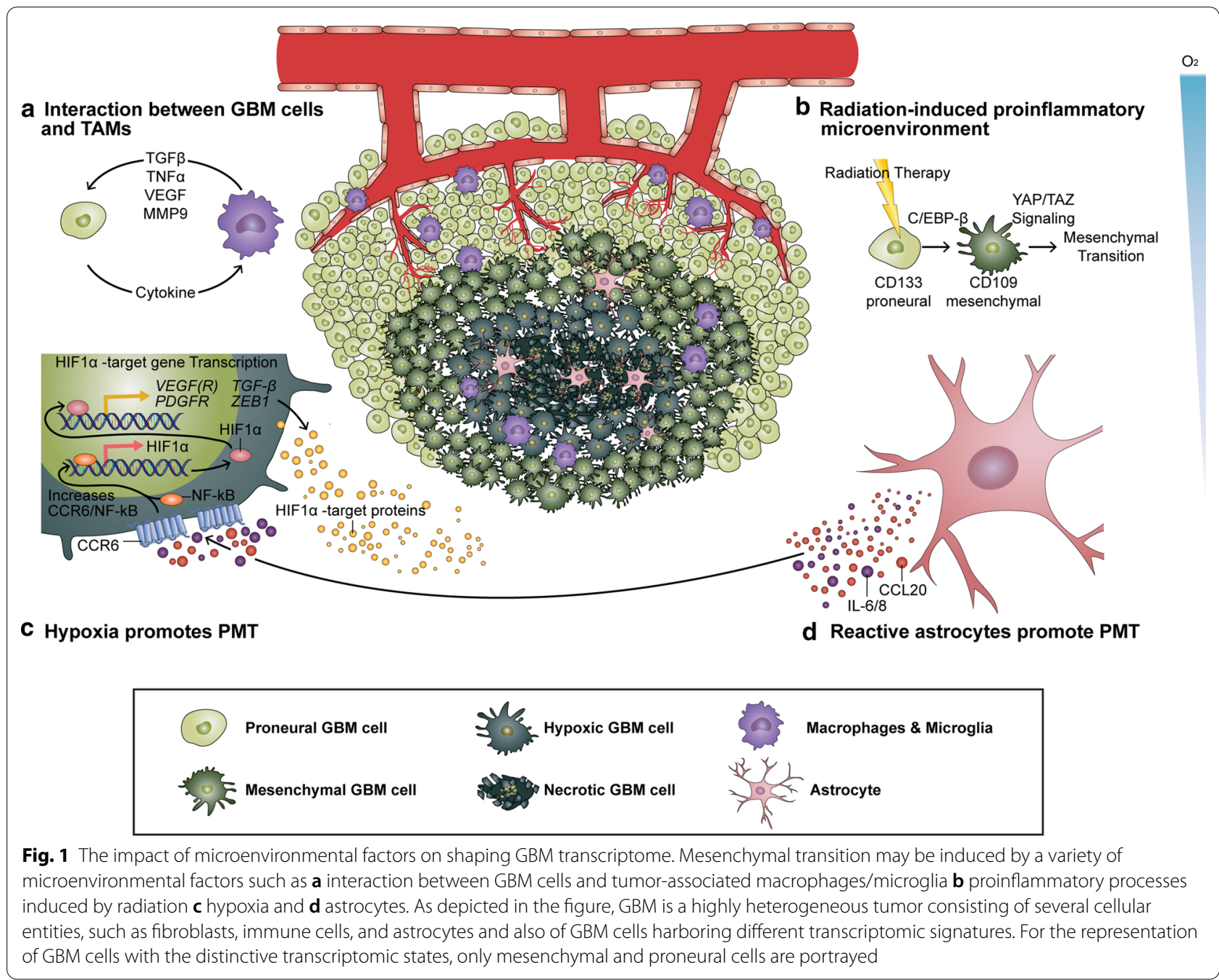


mesenchymal phenotype can be shaped by a variety of infiltrative immune cells $[32,178]$. TAMs, being the largest stromal population in GBM, are generally described as integral microenvironmental components contributing to mesenchymal transition by expressing pro- (M1) (e.g., TNF $\alpha$ ) and anti-inflammatory (M2) (e.g., TGF $\beta$ ), pro-angiogenic (e.g., VEGF), and extracellular matrix remodeling factors (e.g., MMP9) (Fig. 1a) [11, 35, 119]. Also, TAMs have been shown to release a family of cytokines, which may mediate mesenchymal differentiation in an NF-kB-dependent manner. Likewise, many studies reported that mesenchymal GBM exhibits a high degree of macrophages/microglia infiltration and also necrosis compared to other transcriptional subclasses $[25,114,155]$.

Heterogeneous transcriptional state of GBM cells in the tumor microenvironment can also be explained in the context of anatomical heterogeneity, which consists of various histological features [121]. Puchalski et al. utilized laser microdissection to isolate RNA from these regions and demonstrated that many of the critical mesenchymal-related signatures (e.g., HIF- $1 \alpha$ network, TNF $\alpha$ signaling pathway, cell migration, and immune response) are enriched in perinecrotic/pseudopalisading zones. Similarly, necrosis was found to impact the transcriptional class of GBM in a way that non-mesenchymal signatures became more molecularly similar to the mesenchymal class with increasing levels of necrosis [11,25]. However, more single-cell-based research is needed to determine whether glioma cells in perinecrotic/pseudopalisading areas intrinsically exhibit mesenchymal signature as these anatomical zones have been reported to harbor more TAMs than other parts of the tumor [9, 67].

Radiation-induced vascular permeability is also known to play a critical role in the process of mesenchymal transition as it has been found to result in infiltration of immune cells into the brain parenchyma and subsequently create highly immunologically active milieu through which macrophages/microglia contribute to PMT [11, 35]. Furthermore, Minata et al. have recently found that GBM cells express CD109 protein via C/EBPb in response to the radiation-induced proinflammatory microenvironment and that CD109 drives oncogenic signaling through TAZ/YAP cascade which subsequently results in PMT (Fig. 1b) [91]. Such work has revealed that the interplay between the microenvironment and master mesenchymal regulators may further enhance the plasticity of GBM transcriptome.

Another critical feature of GBM microenvironment is hypoxia, which is a key driver of both tumor growth and angiogenesis $[29,49]$. Hypoxic cells have been shown to activate pro-angiogenic factors, including VEGF/ VEGFR, TGF $\beta$, and PDGFR through the stabilization of
HIF-1/2 $\alpha$, and subsequent HIF-induced transcriptional changes elicit the recruitment of inflammatory cells, and of particular importance, the PMT (Fig. 1c) [29, 92]. For example, Joseph et al. have demonstrated that hypoxia enhances the invasive capacity of GBM cells by promoting HIF1 $\alpha$-ZEB1 axis-mediated mesenchymal transition [61]. Of note, chronic anti-angiogenic therapy was found to lead to excessive pruning of tumor vessels potentiating hypoxia, which, in turn, exacerbates inflammatory and angiogenic microenvironment and subsequently promotes PMT $[92,115]$. These results may partly explain the treatment failure of anti-angiogenic therapy in GBM patients [43]. From these observations, it is likely that each tumor microenvironmental factor cooperates with each other to form a vicious circle of interactions through which mesenchymal transition is promoted.

Additionally, astrocytes, which co-exist with GBM cells in the hypoxic microenvironment, were found to release IL-6, -8 and CCL20, which up-regulate HIF- $1 \alpha$ in a CCR6/NF- $\mathrm{kB}$ signaling-dependent manner and thereby helping GBM cells better adapt to hypoxia (Fig. 1d) [59]. The possible involvement of astrocytes in contributing to mesenchymal transition is further corroborated by a recent study by Niklasson et al. who found that the signature of mesenchymal GBM recapitulates the reactive astrocyte cell state [101].

\section{Metabolic factors}

Genomic abnormalities in genes encoding critical metabolic enzymes have long been recognized to be associated with pathogenesis [94, 171]. Altered energy metabolism may also impact the transcriptomic signature of GBM, which is a rapidly growing tumor with high proliferation index and neighboring geographic necrosis [151].

Especially, as the Warburg effect states, glucose metabolism in neoplastic cells is primarily characterized by increased glucose uptake and enhanced aerobic glycolysis, converting glucose into pyruvate which eventually results in increased production of lactate [41]. Not surprisingly, it has been reported that glycolytic activity was significantly increased in mesenchymal GBM relative to proneural GBM, and the highly glycolytic nature of mesenchymal GBM may indicate its propensity to metabolize glucose to lactic acid at an elevated rate (Fig. 2) [1, $23,86]$. Subsequently, when lactate is exported into the extracellular space through monocarboxylate transporters (MCTs), the tumor environment becomes acidic, which results in a local inflammatory response consisting of various immune cells, including TAMs. These cells, in turn, secrete cytokines and growth factors that promote mesenchymal-related characteristics in GBM cells $[44,107,138]$. It is also suggested that lactate promotes an immune-permissive microenvironment partly 


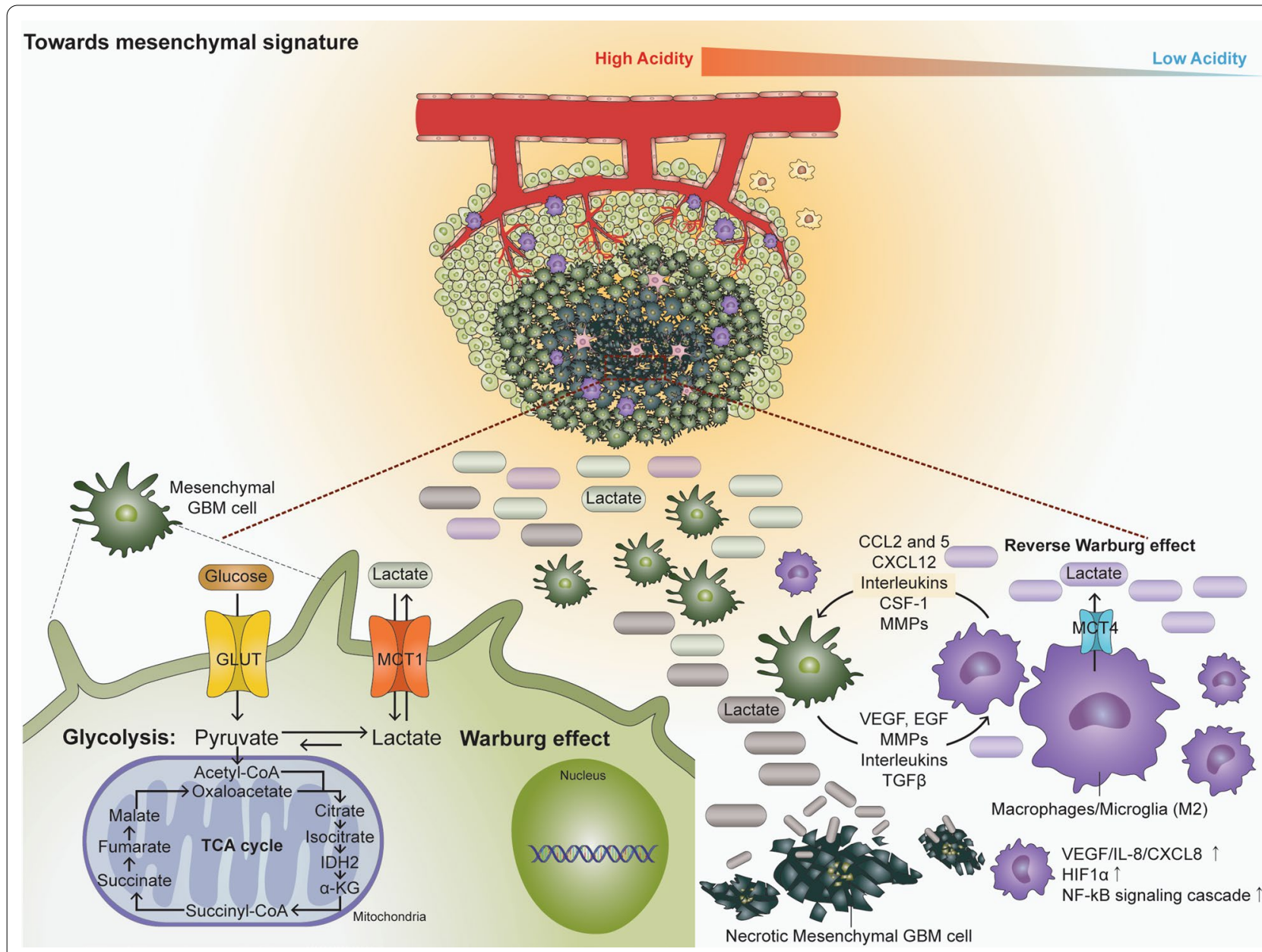

Fig. 2 The impact of metabolic factors on shaping GBM transcriptome. Metabolic alterations associated with the mesenchymal signature of GBM. The three possible sources of lactate in GBM tumor are mesenchymal GBM cells, necrotic GBM cells, and macrophages/microglia present in the microenvironment of the tumor. Compared to GBMs of other transcriptional subtypes, mesenchymal GBM is characterized by a high production rate of lactate, which intensifies the acidity of the tumor microenvironment. Furthermore, the interaction between GBM cells and the attracted macrophages/microglia further promotes the mesenchymal property of the tumor

by stimulating the polarization of resident macrophages to the M2 state [22, 127]. Additionally, lactate has been reported to stabilize HIF- $1 \alpha$, activate NF- $\mathrm{kB}$ signaling cascade, and also induce secretion of VEGF from tumor-associated stromal cells, all of which are the characteristics of mesenchymal GBM [112, 141, 154, 155]. Interestingly, according to the reverse Warburg effect, these immune cells of recruited TAMs may also up-regulate MCT4 in an HIF- $1 \alpha / \mathrm{NF}-\kappa \mathrm{B}$ dependent manner, resulting in increased synthesis and export of lactate that may exacerbate the acidity of the tumor microenvironment and further enhance the glycolytic capacity of GBM cells $[111,147,165]$. Notably, it has been reported that mesenchymal GBM exhibits a high degree of necrosis compared to non-mesenchymal subtypes and that lactate accumulation is known to often occur within areas of necrosis, suggesting that necrotic mesenchymal GBM cells may also be an additional source of lactate in the tumor microenvironment (Fig. 2) [65].

The potential relevance of lactate in promoting the mesenchymal signature was further supported by Heiland et al. who investigated the landscape of metabolomics-transcriptomic alterations in GBM [51]. They showed that metabolites such as choline and lactate are closely associated with immune- and hypoxia-related clusters, both of which show strong enrichment in the mesenchymal signature of GBM [51]. Although a more precise and mechanistic role of dysregulated metabolism in promoting mesenchymal GBM still remains to be elucidated, these studies imply that certain metabolic features may foster the mesenchymal features as tumor progresses in an angiogenic and hypoxic tumor microenvironment [146]. 


\section{Treatment-related factors}

Although the current standard treatment resulted in the improvement of median overall survival of GBM patients from 12.1 to 14.6 months, the disease often progresses within 7-10 months, with the 2-year survival rate less than $20 \%[103,176]$. Such treatment failures and the high rate of recurrence of GBM have now been partly attributed to treatment-induced phenotypic and genomic changes in the recurrent tumors, and/or PMT. A typical pattern of tumor re-growth from proneural signature towards mesenchymal phenotype after surgical resection followed by various treatments is illustrated in Fig. 3.

Firstly, the therapeutic failure may be attributed to radiation therapy, which may ultimately induce mesenchymal transition in tumor as reported in many studies $[9,11$, 47, 70, 91, 166, 184]. Mechanistically, radiation-induced

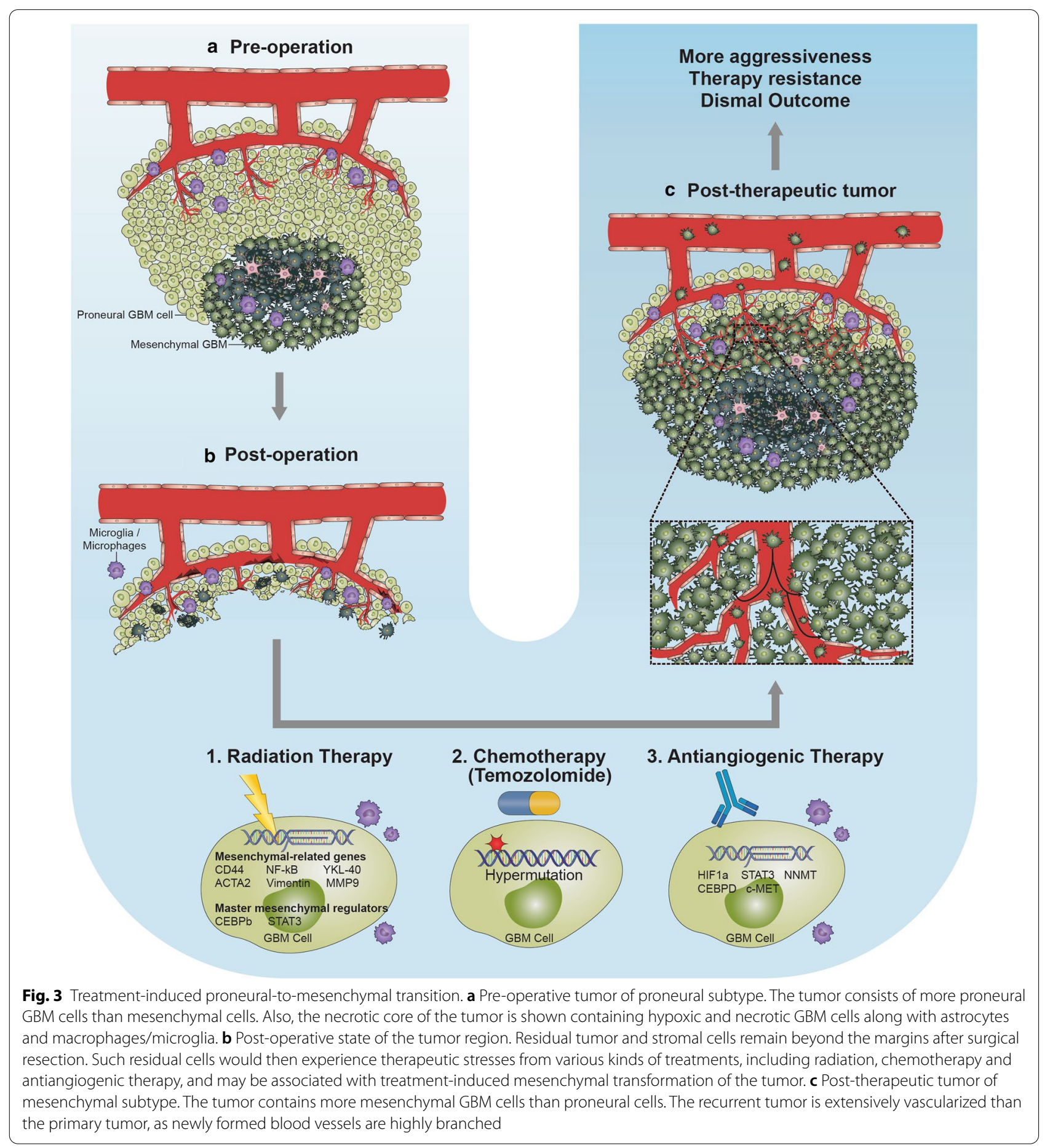


mesenchymal transition is accompanied by the upregulation of CD44 and activation of NF-kB pathways. Particularly, radiation treatment triggered the expression of master mesenchymal regulators, such as $\mathrm{C} / \mathrm{EBPb}$ and STAT3, and also mesenchymal proteins, including YKL-40, COL1A1, ACTA2, Vimentin, and MMP9, many of which are also the key players in EMT $[47,70]$. Importantly, these radiotherapy-associated changes have been found to contribute to the poor response to postradiation treatment and subsequently dismal outcome of the patients, implying a vicious circle of the radiation and the radiation-associated aftereffects [11]. Cellularly, radiation-induced transformation was associated with increased cellular motility and invasion through the expression of TGF- $\beta$, VEGF, and epidermal growth factor, whose blockade enhanced the radiation response [150, 187]. Radiation-induced mesenchymal transition has also been observed in other types of malignancy, such as colorectal cancer [64].

Based on these observations, many studies have been conducted to identify therapeutics that may prevent post-radiation side effects. Adhesion G-protein-coupled receptor, or GPR56/ADGRG1, has been found to inhibit mesenchymal differentiation and the associated radioresistance by targeting the NF- $\mathrm{kB}$ signaling pathway [93]. Also, YM155, a purported radiosensitizer, has been shown to prevent radiation-induced invasion in GBM by targeting STAT3 [184]. Furthermore, STAT3 blockade such as JAK2 inhibitors (AZD1480 or ruxolitinib) was found to augment the therapeutic efficacy of radiation and subsequently abrogate the mesenchymal signature in GBM [70].

Another type of therapy found to be linked to mesenchymal transformation in GBM is anti-angiogenic therapy. Due to a prominent neovascularity of GBM, antiangiogenic therapy, such as bevacizumab and/or sunitinib, was considered hopeful in treating GBM tumors of both newly diagnosed and recurrent. However, in a large prospective phase III trial, the use of adjuvant bevacizumab resulted only in the improvement of progressionfree survival from 1.5 to 4.2 months but not in the overall survival $[19,43,73,164]$. Along with the glioma stem cell accumulation, the failure of anti-angiogenic therapy has largely been attributed to mesenchymal transformation in GBM cells $[77,115,116]$. Piao et al. have demonstrated that predominant biological processes occurring after the antiangiogenic therapy are the upregulation of genes involved in mesenchymal-related pathways, cellular migration and invasion, and also the influx of immune cells secreting chemokines and cytokines, which may act in an autocrine or paracrine fashion to potentiate mesenchymal shift in glioma cells $[27,96,115]$. Furthermore, bevacizumab has been reported to increase the uptake of glucose and its conversion into lactate, which may increase the acidity of the tumor microenvironment [36].

Additionally, whether TMZ-associated therapeutic effect, such as TMZ-induced mutagenesis, might partly and/or indirectly contribute to mesenchymal transition is worthy of further investigation [7, 60]. TMZ-induced hypermutated GBMs at recurrence was found to be associated with an increased frequency of $\mathrm{CD} 8^{+}$lymphocytes [161], which were also found to be present at a higher density in mesenchymal GBM than GBMs of other transcriptional subtypes [120].

Furthermore, although extracranial metastasis of GBM is extremely rare, occurring in less than $2 \%$ of the patients, GBMs have been reported to metastasize to other organs such as lungs and soft tissue of the posterior neck at the time of recurrence [126]. Based on the characteristics of mesenchymal GBM cells, it is likely that these cells may possess greater ability to metastasize extracranially, as their invasive and migratory capacity is highly increased.

All these studies collectively indicate that PMT, or mesenchymal transition in general, is a characteristic phenomenon of GBM cells in response to treatments. However, it is again important to note that $55 \%$ of tumors from IDH-wildtype GBM patients retained their original transcriptional subtype at recurrence [161], raising controversy over preclinical studies mentioned herein or implying a reversible phenotypic shift of non-mesenchymal-to-mesenchymal-to-non-mesenchymal transition. Therefore, more research is needed to reduce the discrepancy between the results obtained from preclinical and large-scale analysis of clinical datasets. Such research will be key to maximize the potential of bench-to-bedside translation for efficient adjuvant GBM therapy.

\section{Therapeutic strategies against transcriptomic plasticity}

The aforementioned characteristics of transcriptomic plasticity raise several critical clinical implications for GBM therapy. It is now evident that standard-of-care first-line treatment is insufficient to effectively abolish GBM whose transcriptome is capable of evolving into a distinct and more aggressive phenotype. The apparent transcriptomic plasticity of GBM suggests that the treatment regimen for GBM should also consider the oncogenic pathways that may distinctively be activated as tumor progresses and also that targeted therapy should be applied concurrently or as a part of multimodal treatment strategy.

To address this issue, several novel therapeutic modalities have been developed and intensively studied [14, 46, $56,85]$. Especially, specific inhibitors of the mesenchymal phenotype in combination with other therapeutic 
regimen have been suggested to synergistically inhibit GBM progression and/or mesenchymal transition [10, 11, 70]. Nevertheless, multidrug therapies could be associated with treatment complications as it was reported by Batchelor et al. who showed that the combination of TMZ with bevacizumab resulted in high toxicity and intracranial hemorrhage in a group of patients [8].

As previously discussed, TAMs are the major tumor microenvironmental cell types that play a critical role in the process of mesenchymal transformation in GBM, and therefore, targeting TAMs may be a viable therapeutic approach to not only augment the therapeutic efficacy of radiotherapy [2], but also impede the subsequent mesenchymal transition. The translational potential of targeting TAMs was investigated by Pyonteck et al. who used BLZ945, which is a brain-penetrant inhibitor of colony stimulating factor-1 receptor (CSF-1R), to target TAMs and demonstrated a significant increased survival in the treated mice [122]. An interesting observation from this study was that CSF-1R blockade did not affect the number of TAMs, but rather, decreased pro-tumorigenic M2 markers in TAMs, suggesting that TAMs are "re-educated" to perform antitumor activity. Furthermore, it was shown that CSF-1R inhibition by PLX3397, which hampers the tyrosine kinase activity of CSF-1R, prevented radiation-recruited monocytes from differentiating into immunosuppressive and pro-tumorigenic M2 macrophages [131, 143, 170]. Of note, GBMs may also develop resistance to sustained CSF-1R blockade. It was observed that $>50 \%$ of tumors relapsed after BLZ945 treatment. However, combined treatment of BLZ945 with blockades for either insulin-like growth factor-1 receptor (IGF-1R) or phosphatidylinositol 3-kinase (PI3K), the activities of which were found to be elevated in recurrent GBM, resolved the resistance to CSF-1R inhibitor [123]. Similarly, PLX3397 alone was not found effective in treating recurrent GBMs in a phase II clinical trial, suggesting that a combined therapy may be needed to augment the potential efficacy of targeting CSF-1R in GBM [13].

Unfortunately, to our knowledge, there has been no study investigating the therapeutic efficacy of CSF-1R inhibition specifically on mesenchymal GBM or whether it can prevent subtype transitioning into mesenchymal signature. The genetically engineered mouse models of glioma used by Akkari et al. to examine the combined therapeutic efficacy of CSF-1R inhibitor and radiotherapy were generated in an Ink4a/Arf-deficient background (platelet-derived growth factor-driven Ink4a/Arf KO), which was previously reported to closely resemble the proneural subtype of GBM $[2,47]$. Given a tight association between mesenchymal GBM and the abundance of infiltrated TAMs, it would be worth investigating if mesenchymal GBM would represent the most sensitive subtype to CSF-1R inhibition compared to other transcriptional subtypes $[11,131,137]$. Of note, the two recurrent GBM patients who had best progression-free survival after PLX3397 treatment in a phase II clinical trial were found to exhibit the mesenchymal signatures [13]. Additionally, since TAMs have also been reported to be associated with angiogenesis, vasculogenic mimicry and revascularization after radiation in GBM xenografts, it will also be instructive to examine the synergistic effect of CSF-1R inhibitors with anti-angiogenic therapy, which was shown effective in high-grade serous ovarian cancer $[80,129,162]$.

Oncolytic virotherapy may also circumvent mesenchymal transition in GBM by promoting the polarization state of TAMs as pro-inflammatory and antitumoral M1 phenotype. As it was discussed in the recent review by Zhang and Liu, genetically modified oncolytic viruses expressing immunomodulatory transgenes have been considered as a promising therapeutic tool for glioma treatment [182]. Combined treatment of oncolytic herpes simplex virus expressing IL-12 with two checkpoint inhibitors (anti-CTLA-4 and anti-PD-1) resulted in the regression of GBM tumor in a preclinical mouse model and, interestingly, this treatment was found to be associated with influx of macrophages of M1-like polarization state [132]. Moreover, the effectiveness of the oncolytic adenovirus Delta24-RGD was investigated which produced a prolonged M2 to M1 TAMs phenotype shift in GBM, suggesting that oncolytic virotherapy may be applied to modulate radioresistance [152, 161]. Notably, the synergistic effect of oncolytic virotherapy with radiotherapy or TMZ was also reported, raising a feasibility that oncolytic virus may effectively be used with standard-of-care treatment $[6,42,75]$. Further studies are needed to determine whether oncolytic virotherapy prevents subtype plasticity and/or mesenchymal transformation in GBM.

Genomic aberrations in neurofibromin 1 (NF1) gene have been reported as one of the major characteristics of the mesenchymal GBM, and NF1 deficiency has been shown to recruit TAMs to the tumor site, indicating that reconstituting functional NF1 may prevent mesenchymal transformation in GBM $[155,161]$. As reviewed by Leier et al. biotechnology-based therapeutic strategies, such as cDNA replacement, CRISPR-based DNA repair and exon skipping, are being developed as a form of mutationdirected therapies to repair the NF1 gene [71]. Furthermore, since the loss of NF1 in glial cells has been found to be associated with increased RAS activity, targeting the RAS-downstream signaling pathways (e.g., the RAFMEK-ERK signaling cascade) through MEK inhibition may be another viable therapeutic strategy to prevent 
NF1-associated mesenchymal transformation in GBM $[17,57,78]$.

Currently, salvage therapy for the recurrent GBMs generally includes reoperation, fractionated re-irradiation, re-chemotherapy, gamma knife radiosurgery (GKRS) and various kinds of targeted therapies, which are usually applied to patients in clinical trials [95]. Among these, GKRS has been placed as one of the attractive and relatively safe salvage treatments for the recurrent GBMs [39, 69]. Dual treatment of radiosurgery and bevacizumab was reported to benefit both the overall (11.2-17.9 months) and progression-free survival (3.9-14.9 months) of GBM patients $[95,106]$. This indicates that the combination of salvage GKRS and adjuvant chemotherapy may offer a novel treatment option to improve the prognosis of patients with recurrent mesenchymal GBMs.

Nonetheless, tumors may also progress after GKRS and it has been reported that the patterns of recurrence are similar to those of conventional radiation, implying the possible development of the mesenchymal signature in GKRS-induced response in tumor [106]. Importantly, symptomatic radionecrosis, which commonly results from avascularized tissue at the site of the GKRS target, is a well-recognized treatment risk of stereotactic radiosurgery [109]. Telangiectasis was observed to be the most prominent vasculature in the radionecrotic and/or perinecrotic region where the abundant expression of VEGF was concomitantly observed, and the reactive astrocytes, which were intensively distributed in this area, were found to be a major source of VEGF production [102]. Similarly, Yoritsune et al. reported that the perinecrotic area formed after intensive radiotherapy is mainly infiltrated by two distinct cell populations-reactive astrocytes and microglias, which were found to express VEGF and HIF- $1 \alpha$, respectively [175]. These studies imply that GKRS-induced symptomatic radionecrosis may be an indicator of the development of mesenchymal GBM. Although GKRS-associated transcriptomic changes have not been reported to date, it may be speculated that focal radiation may strongly activate the master mesenchymal regulators, suggesting that the therapeutic intervention of mesenchymal inhibitors may be needed to circumvent GKRS-associated complications.

Thermotherapy has also been described as a promising therapeutic modality for both newly diagnosed and recurrent GBMs and a growing body of evidence implies that it may be used as a salvage treatment option for the therapy-resistant mesenchymal GBMs. Laser interstitial thermal therapy (LITT) is a minimally invasive thermal ablation approach that surgically addresses not only symptomatic radionecrosis, but also high-grade gliomas that are treatment refractory and/or unresectable [52, 53, 136]. LITT has been reported to promote the disruption of the blood-brain barrier, thereby enhancing the effects of adjuvant chemotherapies [52,136], suggesting that dual treatment of LITT and mesenchymal inhibitors may be useful in treating recurrent mesenchymal GBMs [54]. Another type of thermotherapy is magnetic hyperthermia, which generates heat by magnetic nanoparticles in response to the application of an external alternating magnetic field [83, 87]. Alongside producing a localized thermo-ablative effect, the therapeutic potential of magnetic hyperthermia has been described based on its synergistic effect as a chemoradiosensitizer [63, 84], and also immunomodulatory effect [140]. These suggest that magnetic hyperthermia may be applied to modulate the immunosuppressive microenvironment of mesenchymal GBM patients. Of note, such heat-based therapies have been associated with elevated expression of the family of heat shock proteins, which may reduce the efficacy of subsequent thermotherapies [34]. It has been reported that thermotolerance may be achieved by the expression of HSP90, HSP70 and HSP27, which have also been suggested to promote mesenchymal transformation in GBM [125], indicating that mesenchymal inhibitors may be needed to prevent possible thermotherapy-associated transcriptomic shift.

The synergistic and possible adverse effects of the combined therapeutic modalities, including those described here, must be actively investigated to optimize the therapeutic design and to add to the armamentarium of the current standard-of-care with the goal of impeding mesenchymal transformation in GBM.

\section{Biomarkers and therapeutic targets for mesenchymal glioblastoma}

In addition to the master mesenchymal regulators, there are a number of genes and molecules which have been identified, through a large-scale transcriptomic analysis, as both biomarkers and therapeutic targets for mesenchymal GBM. The understanding of their interactions with each other, with master mesenchymal regulators, and also with the tumor microenvironmental factors will offer an instrumental opportunity to develop an effective and selective therapeutic modality for mesenchymal GBM patients.

As mentioned previously, one of the most well-defined biomarkers for mesenchymal GBM is genomic aberration in NF1 locus. While EGFR and PDGFRA amplifications are the major genomic abnormalities in classical and proneural GBMs, respectively, deficiency in NF1, mainly via homozygous and hemizygous deletions, was observed as a highly frequent event in mesenchymal GBMs, and the pathobiological significance of such loss was associated with the infiltration of TAMs into the tumor microenvironment followed by PMT and radioresistance [11, $130,155,161]$. 
Chong et al. based on the association of cell surface sialyation with tumor cell invasiveness, investigated the role of ST3GAL1 sialytransferase gene in GBM and found that this is triggered by TGF $\beta$ signaling pathway typically in mesenchymal GBM and also regulates gliomagenesis via APC/C-Cdh1-targeted control of FoxM1 protein degradation. Particularly, they showed that ST3GAL1-associated transcriptomic program favors the mesenchymal signature of GBM and is predictive of patient survival, suggesting that ST3GAL1-related processes may be a viable therapeutic target [20]. Also, S100A4, a gene that encodes a small calcium binding protein, was found as a critical upstream regulator of both EMT-associated proteins, including SNAIL2 and ZEB1, and some of the important mesenchymal signature genes in GBM, suggesting S100A4 as a critical mesenchymal marker and therapeutic target [21]. Additionally, prosaposin, which is a conserved glycoprotein with multiple biological functions, has recently been presented as a novel targetable biomarker for the treatment of mesenchymal GBM mainly because prosaposin plays a regulatory role in GBM invasion and PMT through TGF $\beta 1 /$ Smad signaling pathway [58]. Another critical modulator recently identified for mesenchymal GBM is sortilin, which is a member of the Vps10p sorting receptor family found to promote GBM invasion mainly via glycogen synthase kinase 3 beta (GSK-3 $\beta) / \beta$-catenin/Twist-induced mesenchymal transition, suggesting that AF38469, a novel inhibitor of sortilin, may be a selective antitumor agent for sortilinoverexpressing mesenchymal GBM [172]. Furthermore, anti-apoptotic protein, such as BIRC3, has been identified as a biomarker for mesenchymal GBM habitats in the hypoxic microenvironment. The expression of BIRC3 was found to correlate with that of HIF- $1 \alpha$ in a hypoxic tumor region, and it was shown that BIRC3 is a key molecule mediating the survival adaptation in hypoxia-driven mesenchymal GBM habitats [157]. Given a tight association of the mesenchymal subtype and a high degree of tumor necrosis, an enzyme such as transglutaminase 2, or TGM2, was found as a key molecular switch of necrosis-induced mesenchymal differentiation by regulating the master mesenchymal transcription factors [174].

Some microRNAs (miRNAs) have also been identified to be associated with mesenchymal GBM. miRNAs are non-coding RNAs ranging from 18 to 24 nucleotides in length that negatively regulate gene expression at the post-transcriptional level [55]. Their expression may be either contributory or inhibitory to various types of cancers, including GBM [110, 160]. One of the miRNAs found critical for mesenchymal transition in GBM is miR-23a, which was found to induce the expression of invasion- and PMT-related molecules, including RhoA, RhoC, Snail, Slug, and MMP9 [168]. On the other hand,
miR-504 was found to suppress the aggressive biological processes related with the mesenchymal phenotype of GBM primarily through negatively regulating FZD7mediated Wnt- $\beta$-catenin pathway, and, correspondingly, low miR-504/FZD7 expression ratio was found as a mesenchymal subtype marker and prognostic indicator for GBM patients [76].

The summary of the recent findings of potential targets and biomarkers for mesenchymal GBM, including those mentioned herein, is presented in Table 1 . It seems that a diverse class of molecules contribute to the acquisition of the mesenchymal transcriptome in GBM. Understanding their collective involvement in the establishment of the mesenchymal signature during GBM progression will be critical to salvage patients failing multimodal therapeutic approaches applied today.

\section{Concluding remarks}

Despite much effort to characterize GBM at molecular and cellular levels, GBM still remains the most challenging solid primary tumor of the central nervous system. The large-scale genomic and transcriptomic profiling of GBMs at the various levels has provided an unprecedented knowledge of the dynamic inter- and intratumoral transcriptomic heterogeneity, which is plastic rather than static. In the present review, we have discussed molecular pathobiology associated with mesenchymal transformation in GBM and its clinical relevance; however, additional studies are required to clear several controversies over the prognosis of mesenchymal GBM patients and to target the phenotypic plasticity as an adjuvant therapy.

As evidenced by many studies, the inflammatory nature of mesenchymal GBM suggests that the immunologic status of patients, the heterogeneous activity of both immunostimulatory and immunosuppressive cell types in the tumor immune compartment, and their complex interplay with master mesenchymal regulators must be investigated to understand the impact of inflammatory microenvironment on shaping the mesenchymal signature. Such analysis may help us to develop a more effective immunotherapy for immunologically reactive, and yet, refractory mesenchymal GBMs.

Also, it has now become evident that second-line GBM therapy should consider the molecular characteristics of re-evolved tumor and consist of a targeted therapy specifically aimed at altered molecular features. To this end, a more accurate preclinical model, which effectively recapitulates the molecular characteristics of the original tumor and may be developed in a clinically relevant time frame, is urgently needed to provide a testing ground of combination of various targeted therapies.

In conclusion, GBM cells harness many different kinds of signaling pathways to their advantage to survive the 
Table 1 A list of molecules identified to contribute to the establishment of the mesenchymal signature in GBM

\begin{tabular}{|c|c|c|c|c|}
\hline Category & Name & Identified Mode of Actions & Potent Inhibitor(s) & References \\
\hline \multirow[t]{3}{*}{$\begin{array}{l}\text { Master tran- } \\
\text { scriptional } \\
\text { regulators }\end{array}$} & STAT3 & $\begin{array}{l}\text { Normally operate opposing signals (neurogenesis versus } \\
\text { gliogenesis) combined expression is linked to the mesen- } \\
\text { chymal signature }\end{array}$ & YM155/AZD1480/ruxolitinib & {$[16,70,184]$} \\
\hline & C/EBP $\beta$ & & N/A & \\
\hline & TAZ & TAZ-TEAD interaction / cooperates with PDGF-B & Verteporfin & {$[10,156]$} \\
\hline \multirow[t]{9}{*}{ Other proteins } & S100A4 & $\begin{array}{l}\text { Regulates SNAIL2, ZEB1 and the mesenchymal signature } \\
\text { genes }\end{array}$ & N/A & {$[21]$} \\
\hline & Prosaposin & TGF- $\beta 1 / S m a d$ signaling pathway & LY2109761 (TGF- $\beta 1$ inhibitor) & {$[58]$} \\
\hline & Sortilin & $(G S K-3 \beta) / \beta$-catenin/Twist signaling axis & AF38469 & [172] \\
\hline & BIRC3 & Induced by hypoxia & N/A & [157] \\
\hline & FoxM1 & Activation loop of ADAM17/EGFR/GSK3 $\beta$ & TAPI-2 & [179] \\
\hline & Nrf2 & Positive feedback loop between SQSTM1/p62 and Nrf2 & N/A & [118] \\
\hline & PBX3 & Activation of MEK/ERK1/2 & N/A & [167] \\
\hline & \multirow[t]{2}{*}{ FOXO1 } & \multirow{2}{*}{$\begin{array}{l}\text { Regulates mesenchymal marker proteins ( } \mathrm{N} \text {-cadherin, } \\
\text { Vimentin, CD44, and YKL-40) }\end{array}$} & AS1842856 (type 2 diabetes mellitus) & {$[97]$} \\
\hline & & & SIN3a (hepatic insulin sensitivity) & {$[68]$} \\
\hline \multirow[t]{3}{*}{ Enzymes } & ST3GAL1 & TGF $\beta$ signaling pathways & SB431542 (TGF $\beta$ inhibitor) & [20] \\
\hline & & & AL10 (lung cancer) & [18] \\
\hline & TGM2 & $\begin{array}{l}\text { Regulates C/EBP } \beta \text { expression directly by polymerization of } \\
\text { GADD153 via NF-KB activation }\end{array}$ & GK921 & [174] \\
\hline \multirow[t]{4}{*}{ microRNAs } & miR-23a & miR-23a/HOXD10 axis & N/A & [168] \\
\hline & miR-10b & HOXD10/NOTCH1/TP53/PAX6 axis & N/A & {$[74]$} \\
\hline & miR-504 & $\begin{array}{l}\text { Negatively regulates FZD7-mediated Wnt- } \beta \text {-catenin } \\
\text { pathway }\end{array}$ & N/A & [76] \\
\hline & miR-128a/miR-504 & $\begin{array}{l}\text { Negatively regulates expression of mesenchymal markers } \\
\text { (YKL-40, CD44, and Vimentin) }\end{array}$ & N/A & [82] \\
\hline
\end{tabular}

therapy-insulted microenvironment; therefore, multidisciplinary therapeutic approaches, which are optimized to the unique biology of brain, should be encouraged as they may provide synergistic effects against the progressing tumor $[45,149]$. In this regard, the addition of master mesenchymal regulator inhibitors may be a viable second-line therapeutic option as it may circumvent therapy-associated transcriptomic alterations in the recurrent tumor. Thus, the identification of additional master transcriptional regulators and their corresponding inhibitors may significantly improve not only the current understanding of the seemingly complex transcriptional regulatory network of mesenchymal GBM, but also the treatment response of patients with mesenchymal tumors at recurrence.

\footnotetext{
Abbreviations

2-HG: 2-hydroxyglutarate; a-KG: a-ketoglutarate; CSF-1R: colony stimulating factor-1 receptor; GSK-33: glycogen synthase kinase 3 beta; GBM: glioblastoma; GKRS: gamma knife radiosurgery; IGF-1R: insulin-like growth factor-1 receptor; LITT: laser interstitial thermal therapy; MCTs: monocarboxylate transporters; miRNAs: MicroRNAs; NF-KB: nuclear factor-KB; NF1: neurofibromin 1; PI3K: phosphatidylinositol 3-kinase; PMT: proneural-to-mesenchymal transition; EMT: epithelial-to-mesenchymal transition; TMZ: temozolomide; TCGA: the cancer genome atlas; TAMs: tumor-associated macrophages and microglia;
}

TAZ: transcriptional coactivator with PDZ-binding motif; TEAD: transcriptional enhanced associate domain;"VEGF: vascular endothelial growth factor.

\section{Authors' contributions}

YK carried out the literature searches, wrote the first draft, and developed the figures. FSV reviewed and revised the manuscript, and gave valuable feedback. SHP, BWY, HRP and CL provided thorough guidance and GBM expertise in writing the manuscript and generating the figures. RGWV and SHP critically revised the manuscript and approved the final version. All authors read and approved the final manuscript.

\section{Funding}

The Paek laboratory is supported by the Korea Healthcare Technology R\&D Project (Grant HI1 1C21 100200, H118C0886), funded by the Ministry of Health \& Welfare, Republic of Korea; the Industrial Strategic Technology Development Program (Grant 10050154, Business Model Development for Personalized Medicine Based on Integrated Genome and Clinical Information) funded by the Ministry of Trade, Industry \& Energy (MI, Korea); the Original Technology Research Program for Brain Science through the National Research Foundation of Korea (NRF) funded by the Ministry of Education, Science and Technology (Grant 2015M3C7A1028926, 2017M3C7A1044367); the Original Technology Research Program for Brain Science through the NRF funded by the Ministry of Education, Science and Technology (2017M3C7A1047392); the Bio \& Medical Technology Development Program of the National Research Foundation (NRF) funded by the Ministry of Science \& ICT (Grant Number: 2020M3A9G802202921).

Availability of data and materials Not applicable. 


\section{Declaration}

\section{EEthics approval and consent to participate}

Not applicable.

\section{Consent for publication}

Not applicable.

\section{Competing interests}

The authors declare that they have no competing interests.

\begin{abstract}
Author details
1 Department of Neurosurgery, Cancer Research Institute and Ischemic/ Hypoxic Disease Institute, Seoul National University College of Medicine, Seoul 03080, Korea. ${ }^{2}$ The Jackson Laboratory for Genomic Medicine, Farmington, CT 06032, USA. ${ }^{3}$ Department of Neurosurgery, Cancer Center Amsterdam, Amsterdam University Medical Centers, VU University Medical Center, Amsterdam, The Netherlands. ${ }^{4}$ Department of Pathology, Seoul National University Hospital, Seoul 03080, Korea. ${ }^{5}$ Division of Hemato-Oncology, Department of Internal Medicine, Inje University Seoul Paik Hospital, Seoul 04551, Korea. ${ }^{6}$ Department of Neurosurgery, Soonchunhyang University Seoul Hospital, Seoul 04401, Korea.
\end{abstract}

Received: 27 January 2021 Accepted: 6 March 2021

Published online: 24 March 2021

\section{References}

1. Agnihotri S, Zadeh G (2016) Metabolic reprogramming in glioblastoma: the influence of cancer metabolism on epigenetics and unanswered questions. Neuro Oncol 18:160-172. https://doi.org/10.1093/neuonc/ nov 125

2. Akkari L, Bowman RL, Tessier J, Klemm F, Handgraaf SM, de Groot M, Quail DF, Tillard L, Gadiot J, Huse JT et al (2020) Dynamic changes in glioma macrophage populations after radiotherapy reveal CSF$1 \mathrm{R}$ inhibition as a strategy to overcome resistance. Sci Transl Med 12:eaaw7843. https://doi.org/10.1126/scitranslmed.aaw7843

3. Aytes A, Mitrofanova A, Lefebvre C, Alvarez MJ, Castillo-Martin M, Zheng T, Eastham JA, Gopalan A, Pienta KJ, Shen MM et al (2014) Cross-species regulatory network analysis identifies a synergistic interaction between FOXM1 and CENPF that drives prostate cancer malignancy. Cancer Cell 25:638-651. https://doi.org/10.1016/j.ccr.2014.03.017

4. Azam Z, To ST, Tannous BA (2020) Mesenchymal transformation: the rosetta stone of glioblastoma pathogenesis and therapy resistance. Adv Sci (Weinh) 7:2002015. https://doi.org/10.1002/advs.202002015

5. Bahadur S, Sahu AK, Baghel P, Saha S (2019) Current promising treatment strategy for glioblastoma multiform: a review. Oncol Rev 13:417. https://doi.org/10.4081/oncol.2019.417

6. Bai Y, Chen Y, Hong X, Liu X, Su X, Li S, Dong X, Zhao G, Li Y (2018) Newcastle disease virus enhances the growth-inhibiting and proapoptotic effects of temozolomide on glioblastoma cells in vitro and in vivo. Sci Rep 8:11470. https://doi.org/10.1038/s41598-018-29929-y

7. Barthel FP, Johnson KC, Varn FS, Moskalik AD, Tanner G, Kocakavuk E, Anderson KJ, Abiola O, Aldape K, Alfaro KD et al (2019) Longitudinal molecular trajectories of diffuse glioma in adults. Nature 576:112-120. https://doi.org/10.1038/s41586-019-1775-1

8. Batchelor TT, Sorensen AG, di Tomaso E, Zhang WT, Duda DG, Cohen KS, Kozak KR, Cahill DP, Chen PJ, Zhu M et al (2007) AZD2171, a panVEGF receptor tyrosine kinase inhibitor, normalizes tumor vasculature and alleviates edema in glioblastoma patients. Cancer Cell 11:83-95. https://doi.org/10.1016/j.ccr.2006.11.021

9. Behnan J, Finocchiaro G, Hanna G (2019) The landscape of the mesenchymal signature in brain tumours. Brain 142:847-866. https://doi.org/ 10.1093/brain/awz044

10. Bhat KP, Salazar KL, Balasubramaniyan V, Wani K, Heathcock L, Hollingsworth F, James JD, Gumin J, Diefes KL, Kim SH et al (2011) The transcriptional coactivator TAZ regulates mesenchymal differentiation in malignant glioma. Genes Dev 25:2594-2609. https://doi.org/10. 1101/gad.176800.111
11. Bhat KPL, Balasubramaniyan V, Vaillant B, Ezhilarasan R, Hummelink K, Hollingsworth F, Wani K, Heathcock L, James JD, Goodman LD et al (2013) Mesenchymal differentiation mediated by NF-kappaB promotes radiation resistance in glioblastoma. Cancer Cell 24:331-346. https:// doi.org/10.1016/j.ccr.2013.08.001

12. Bisikirska B, Bansal M, Shen Y, Teruya-Feldstein J, Chaganti R, Califano A (2016) Elucidation and pharmacological targeting of novel molecular drivers of follicular lymphoma progression. Cancer Res 76:664-674. https://doi.org/10.1158/0008-5472.CAN-15-0828

13. Butowski N, Colman H, De Groot JF, Omuro AM, Nayak L, Wen PY, Cloughesy TF, Marimuthu A, Haidar S, Perry A et al (2016) Orally administered colony stimulating factor 1 receptor inhibitor PLX3397 in recurrent glioblastoma: an Ivy foundation early phase clinical trials consortium phase II study. Neuro Oncol 18:557-564. https://doi.org/10. 1093/neuonc/nov245

14. Caccese M, Indraccolo S, Zagonel V, Lombardi G (2019) PD-1/PD-L1 immune-checkpoint inhibitors in glioblastoma: a concise review. Crit Rev Oncol Hematol 135:128-134. https://doi.org/10.1016/j.critrevonc. 2018.12.002

15. Calses PC, Crawford JJ, Lill JR, Dey A (2019) Hippo pathway in cancer: aberrant regulation and therapeutic opportunities. Trends Cancer 5:297-307. https://doi.org/10.1016/j.trecan.2019.04.001

16. Carro MS, Lim WK, Alvarez MJ, Bollo RJ, Zhao X, Snyder EY, Sulman EP, Anne SL, Doetsch F, Colman H et al (2010) The transcriptional network for mesenchymal transformation of brain tumours. Nature 463:318-325. https://doi.org/10.1038/nature08712

17. Cheng Y, Tian H (2017) Current development status of MEK inhibitors. Molecules. https://doi.org/10.3390/molecules22101551

18. Chiang $\mathrm{CH}$, Wang $\mathrm{CH}$, Chang HC, More SV, Li WS, Hung WC (2010) A novel sialyltransferase inhibitor AL10 suppresses invasion and metastasis of lung cancer cells by inhibiting integrin-mediated signaling. J Cell Physiol 223:492-499. https://doi.org/10.1002/jcp.22068

19. Chinot OL, Wick W, Mason W, Henriksson R, Saran F, Nishikawa R, Carpentier AF, Hoang-Xuan K, Kavan P, Cernea D et al (2014) Bevacizumab plus radiotherapy-temozolomide for newly diagnosed glioblastoma. $\mathrm{N}$ Engl J Med 370:709-722. https://doi.org/10.1056/NEJMoa1308345

20. Chong YK, Sandanaraj E, Koh LW, Thangaveloo M, Tan MS, Koh GR, Toh TB, Lim GG, Holbrook JD, Kon OL et al (2016) ST3GAL1-associated transcriptomic program in glioblastoma tumor growth, invasion, and prognosis. J Natl Cancer Inst. https://doi.org/10.1093/jnci/djv326

21. Chow KH, Park HJ, George J, Yamamoto K, Gallup AD, Graber JH, Chen Y, Jiang W, Steindler DA, Neilson EG et al (2017) S100A4 is a biomarker and regulator of glioma stem cells that is critical for mesenchymal transition in glioblastoma. Cancer Res 77:5360-5373. https://doi.org/10.1158/ 0008-5472.Can-17-1294

22. Colegio OR, Chu NQ, Szabo AL, Chu T, Rhebergen AM, Jairam V, Cyrus N, Brokowski CE, Eisenbarth SC, Phillips GM et al (2014) Functional polarization of tumour-associated macrophages by tumour-derived lactic acid. Nature 513:559-563. https://doi.org/10.1038/nature13490

23. Colen CB, Shen Y, Ghoddoussi F, Yu P, Francis TB, Koch BJ, Monterey MD, Galloway MP, Sloan AE, Mathupala SP (2011) Metabolic targeting of lactate efflux by malignant glioma inhibits invasiveness and induces necrosis: an in vivo study. Neoplasia 13:620-632. https://doi.org/10. 1593/neo.11134

24. Conroy S, Kruyt FAE, Wagemakers M, Bhat KPL, den Dunnen WFA (2018) IL-8 associates with a pro-angiogenic and mesenchymal subtype in glioblastoma. Oncotarget 9:15721-15731. https://doi.org/10.18632/ oncotarget.24595

25. Cooper LA, Gutman DA, Chisolm C, Appin C, Kong J, Rong Y, Kurc T, Van Meir EG, Saltz JH, Moreno CS et al (2012) The tumor microenvironment strongly impacts master transcriptional regulators and gene expression class of glioblastoma. Am J Pathol 180:2108-2119. https://doi.org/10. 1016/j.ajpath.2012.01.040

26. Couturier CP, Ayyadhury S, Le PU, Nadaf J, Monlong J, Riva G, Allache R, Baig S, Yan X, Bourgey M et al (2020) Single-cell RNA-seq reveals that glioblastoma recapitulates a normal neurodevelopmental hierarchy. Nat Commun 11:3406. https://doi.org/10.1038/s41467-020-17186-5

27. Crusz SM, Balkwill FR (2015) Inflammation and cancer: advances and new agents. Nat Rev Clin Oncol 12:584-596. https://doi.org/10.1038/ nrclinonc.2015.105 
28. De Craene B, Berx G (2013) Regulatory networks defining EMT during cancer initiation and progression. Nat Rev Cancer 13:97-110. https:// doi.org/10.1038/nrc3447

29. De Palma M, Biziato D, Petrova TV (2017) Microenvironmental regulation of tumour angiogenesis. Nat Rev Cancer 17:457-474. https://doi. org/10.1038/nrc.2017.51

30. Dirkse A, Golebiewska A, Buder T, Nazarov PV, Muller A, Poovathingal S, Brons NHC, Leite S, Sauvageot N, Sarkisjan D et al (2019) Stem cellassociated heterogeneity in Glioblastoma results from intrinsic tumor plasticity shaped by the microenvironment. Nat Commun 10:1787. https://doi.org/10.1038/s41467-019-09853-z

31. Doan NB, Nguyen HS, Alhajala HS, Jaber B, Al-Gizawiy MM, Ahn EE, Mueller WM, Chitambar CR, Mirza SP, Schmainda KM (2018) Identification of radiation responsive genes and transcriptome profiling via complete RNA sequencing in a stable radioresistant U87 glioblastoma model. Oncotarget 9:23532-23542. https://doi.org/10.18632/oncot arget.25247

32. Doucette T, Rao G, Rao A, Shen L, Aldape K, Wei J, Dziurzynski K, Gilbert M, Heimberger AB (2013) Immune heterogeneity of glioblastoma subtypes: extrapolation from the cancer genome atlas. Cancer Immunol Res 1:112-122. https://doi.org/10.1158/2326-6066.CIR-13-0028

33. Dumas AA, Pomella N, Rosser G, Guglielmi L, Vinel C, Millner TO, Rees J, Aley N, Sheer D, Wei J et al (2020) Microglia promote glioblastoma via mTOR-mediated immunosuppression of the tumour microenvironment. EMBO J 39:e103790. https://doi.org/10.15252/embj.2019103790

34. Eldridge BN, Bernish BW, Fahrenholtz CD, Singh R (2016) Photothermal therapy of glioblastoma multiforme using multiwalled carbon nanotubes optimized for diffusion in extracellular space. ACS Biomater Sci Eng 2:963-976. https://doi.org/10.1021/acsbiomaterials.6b00052

35. Engler JR, Robinson AE, Smirnov I, Hodgson JG, Berger MS, Gupta N, James CD, Molinaro A, Phillips JJ (2012) Increased microglia/macrophage gene expression in a subset of adult and pediatric astrocytomas. PLoS ONE 7:e43339. https://doi.org/10.1371/journal.pone.0043339

36. Fack F, Espedal H, Keunen O, Golebiewska A, Obad N, Harter PN, Mittelbronn M, Bahr O, Weyerbrock A, Stuhr L et al (2015) Bevacizumab treatment induces metabolic adaptation toward anaerobic metabolism in glioblastomas. Acta Neuropathol 129:115-131. https://doi.org/10. 1007/s00401-014-1352-5

37. Fan Y, Mao R, Yang J (2013) NF-kappaB and STAT3 signaling pathways collaboratively link inflammation to cancer. Protein Cell 4:176-185. https://doi.org/10.1007/s13238-013-2084-3

38. Fedele M, Cerchia L, Pegoraro S, Sgarra R, Manfioletti G (2019) Proneural-mesenchymal transition: phenotypic plasticity to acquire multitherapy resistance in glioblastoma. Int J Mol Sci. https://doi.org/ 10.3390/ijms20112746

39. Frischer JM, Marosi C, Woehrer A, Hainfellner JA, Dieckmann KU, Eiter H, Wang WT, Mallouhi A, Ertl A, Knosp E et al (2016) Gamma knife radiosurgery in recurrent glioblastoma. Stereotact Funct Neurosurg 94:265-272. https://doi.org/10.1159/000448924

40. Gabrusiewicz K, Li X, Wei J, Hashimoto Y, Marisetty AL, Ott M, Wang F, Hawke D, Yu J, Healy LM et al (2018) Glioblastoma stem cell-derived exosomes induce M2 macrophages and PD-L1 expression on human monocytes. Oncoimmunology 7:e1412909. https://doi.org/10.1080/ 2162402X.2017.1412909

41. Ganapathy-Kanniappan S, Geschwind JF (2013) Tumor glycolysis as a target for cancer therapy: progress and prospects. Mol Cancer 12:152. https://doi.org/10.1186/1476-4598-12-152

42. Geletneky K, Hartkopf AD, Krempien R, Rommelaere J, Schlehofer JR (2010) Improved killing of human high-grade glioma cells by combining ionizing radiation with oncolytic parvovirus $\mathrm{H}-1$ infection. J Biomed Biotechnol 2010:350748. https://doi.org/10.1155/2010/350748

43. Gilbert MR, Dignam JJ, Armstrong TS, Wefel JS, Blumenthal DT, Vogelbaum MA, Colman H, Chakravarti A, Pugh S, Won M et al (2014) A randomized trial of bevacizumab for newly diagnosed glioblastoma. $\mathrm{N}$ Engl J Med 370:699-708. https://doi.org/10.1056/NEJMoa1308573

44. Gottfried E, Kunz-Schughart LA, Ebner S, Mueller-Klieser W, Hoves S, Andreesen R, Mackensen A, Kreutz M (2006) Tumor-derived lactic acid modulates dendritic cell activation and antigen expression. Blood 107:2013-2021. https://doi.org/10.1182/blood-2005-05-1795
45. Gupta K, Burns TC (2018) Radiation-induced alterations in the recurrent glioblastoma microenvironment: therapeutic implications. Front Oncol 8:503. https://doi.org/10.3389/fonc.2018.00503

46. Gupta R, Sharma D (2019) Evolution of magnetic hyperthermia for glioblastoma multiforme therapy. ACS Chem Neurosci 10:1157-1172. https://doi.org/10.1021/acschemneuro.8b00652

47. Halliday J, Helmy K, Pattwell SS, Pitter KL, LaPlant Q, Ozawa T, Holland EC (2014) In vivo radiation response of proneural glioma characterized by protective $\mathrm{p} 53$ transcriptional program and proneural-mesenchymal shift. Proc Natl Acad Sci USA 111:5248-5253. https://doi.org/10.1073/ pnas.1321014111

48. Hambardzumyan D, Gutmann DH, Kettenmann H (2016) The role of microglia and macrophages in glioma maintenance and progression. Nat Neurosci 19:20-27. https://doi.org/10.1038/nn.4185

49. Harris AL (2002) Hypoxia-a key regulatory factor in tumour growth. Nat Rev Cancer 2:38-47. https://doi.org/10.1038/nrc704

50. Harvey KF, Zhang X, Thomas DM (2013) The Hippo pathway and human cancer. Nat Rev Cancer 13:246-257. https://doi.org/10.1038/nrc3458

51. Heiland DH, Worner J, Gerrit Haaker J, Delev D, Pompe N, Mercas B, Franco P, Gabelein A, Heynckes S, Pfeifer D et al (2017) The integrative metabolomic-transcriptomic landscape of glioblastome multiforme. Oncotarget 8:49178-49190. https://doi.org/10.18632/oncotarget.16544

52. Holste KG, Orringer DA (2019) Laser interstitial thermal therapy. NeuroOncol Adv. https://doi.org/10.1093/noajnl/vdz035

53. Hong CS, Deng D, Vera A, Chiang VL (2019) Laser-interstitial thermal therapy compared to craniotomy for treatment of radiation necrosis or recurrent tumor in brain metastases failing radiosurgery. J Neuro-Oncol 142:309-317. https://doi.org/10.1007/s11060-019-03097-z

54. Hormigo A, Mandeli J, Hadjipanayis C, Gnjatic S, Kim-Schulze S, Ghatan S (2019) Phase I study of PD-L1 inhibition with avelumab and laser interstitial thermal therapy in patients with recurrent glioblastoma. J Clin Oncol 37:TPS2074-TPS2074. https://doi.org/10.1200/JCO.2019.37. 15 suppl.TPS2074

55. Iorio MV, Croce CM (2017) MicroRNA dysregulation in cancer: diagnostics, monitoring and therapeutics. A comprehensive review. EMBO Mol Med 9:852. https://doi.org/10.15252/emmm.201707779

56. Jain KK (2018) A critical overview of targeted therapies for glioblastoma. Front Oncol 8:419. https://doi.org/10.3389/fonc.2018.00419

57. Jessen WJ, Miller SJ, Jousma E, Wu J, Rizvi TA, Brundage ME, Eaves D, Widemann B, Kim MO, Dombi E et al (2013) MEK inhibition exhibits efficacy in human and mouse neurofibromatosis tumors. J Clin Investig 123:340-347. https://doi.org/10.1172/JCl60578

58. Jiang Y, Zhou J, Hou D, Luo P, Gao H, Ma Y, Chen YS, Li L, Zou D, Zhang $\mathrm{H}$ et al (2019) Prosaposin is a biomarker of mesenchymal glioblastoma and regulates mesenchymal transition through the TGF-beta1/Smad signaling pathway. J Pathol 249:26-38. https://doi.org/10.1002/path. 5278

59. Jin P, Shin SH, Chun YS, Shin HW, Shin YJ, Lee Y, Kim D, Nam DH, Park JW (2018) Astrocyte-derived CCL20 reinforces HIF-1-mediated hypoxic responses in glioblastoma by stimulating the CCR6-NF-kappaB signaling pathway. Oncogene 37:3070-3087. https://doi.org/10.1038/ s41388-018-0182-7

60. Johnson BE, Mazor T, Hong C, Barnes M, Aihara K, McLean CY, Fouse SD, Yamamoto S, Ueda H, Tatsuno K et al (2014) Mutational analysis reveals the origin and therapy-driven evolution of recurrent glioma. Science 343:189-193. https://doi.org/10.1126/science.1239947

61. Joseph JV, Conroy S, Pavlov K, Sontakke P, Tomar T, Eggens-Meijer E, Balasubramaniyan V, Wagemakers M, den Dunnen WF, Kruyt FA (2015) Hypoxia enhances migration and invasion in glioblastoma by promoting a mesenchymal shift mediated by the HIF1alpha-ZEB1 axis. Cancer Lett 359:107-116. https://doi.org/10.1016/j.canlet.2015.01.010

62. Kaffes I, Szulzewsky F, Chen Z, Herting CJ, Gabanic B, Velazquez Vega JE, Shelton J, Switchenko JM, Ross JL, McSwain LF et al (2019) Human mesenchymal glioblastomas are characterized by an increased immune cell presence compared to proneural and classical tumors. Oncoimmunology 8:e1655360. https://doi.org/10.1080/2162402X.2019.1655360

63. Kampinga $\mathrm{HH}$ (2006) Cell biological effects of hyperthermia alone or combined with radiation or drugs: a short introduction to newcomers in the field. Int J Hyperthermia 22:191-196. https://doi.org/10.1080/ 02656730500532028 
64. Kawamoto A, Yokoe T, Tanaka K, Saigusa S, Toiyama Y, Yasuda H, Inoue Y, Miki C, Kusunoki M (2012) Radiation induces epithelial-mesenchymal transition in colorectal cancer cells. Oncol Rep 27:51-57. https://doi. org/10.3892/or.2011.1485

65. Kennedy KM, Dewhirst MW (2010) Tumor metabolism of lactate: the influence and therapeutic potential for MCT and CD147 regulation. Future Oncol 6:127-148. https://doi.org/10.2217/fon.09.145

66. Klughammer J, Kiesel B, Roetzer T, Fortelny N, Nemc A, Nenning KH, Furtner J, Sheffield NC, Datlinger P, Peter N et al (2018) The DNA methylation landscape of glioblastoma disease progression shows extensive heterogeneity in time and space. Nat Med 24:1611-1624. https://doi. org/10.1038/s41591-018-0156-x

67. Kvisten M, Mikkelsen VE, Stensjoen AL, Solheim O, Van Der Want J, Torp SH (2019) Microglia and macrophages in human glioblastomas: a morphological and immunohistochemical study. Mol Clin Oncol 11:31-36. https://doi.org/10.3892/mco.2019.1856

68. Langlet F, Haeusler RA, Linden D, Ericson E, Norris T, Johansson A, Cook JR, Aizawa K, Wang L, Buettner C et al (2017) Selective inhibition of FOXO1 activator/repressor balance modulates hepatic glucose handling. Cell 171(824-835):e818. https://doi.org/10.1016/j.cell.2017.09.045

69. Larson EW, Peterson HE, Lamoreaux WT, MacKay AR, Fairbanks RK, Call JA, Carlson JD, Ling BC, Demakas JJ, Cooke BS et al (2014) Clinical outcomes following salvage Gamma Knife radiosurgery for recurrent glioblastoma. World J Clin Oncol 5:142-148. https://doi.org/10.5306/ wjco.v5.i2.142

70. Lau J, Ilkhanizadeh S, Wang S, Miroshnikova YA, Salvatierra NA, Wong RA, Schmidt C, Weaver VM, Weiss WA, Persson AI (2015) STAT3 blockade inhibits radiation-induced malignant progression in glioma. Cancer Res 75:4302-4311. https://doi.org/10.1158/0008-5472.CAN-14-3331

71. Leier A, Bedwell DM, Chen AT, Dickson G, Keeling KM, Kesterson RA, Korf BR, Marquez Lago TT, Muller UF, Popplewell L et al (2020) Mutationdirected therapeutics for neurofibromatosis type I. Mol Ther Nucleic Acids 20:739-753. https://doi.org/10.1016/j.omtn.2020.04.012

72. Li CW, Xia W, Huo L, Lim SO, Wu Y, Hsu JL, Chao CH, Yamaguchi H, Yang NK, Ding Q et al (2012) Epithelial-mesenchymal transition induced by TNF-alpha requires NF-kappaB-mediated transcriptional upregulation of Twist1. Cancer Res 72:1290-1300. https://doi.org/10.1158/0008-5472. CAN-11-3123

73. Li Y, Ali S, Clarke J, Cha S (2017) Bevacizumab in recurrent glioma: patterns of treatment failure and implications. Brain Tumor Res Treat 5:1-9. https://doi.org/10.14791/btrt.2017.5.1.1

74. Lin J, Teo S, Lam DH, Jeyaseelan K, Wang S (2012) MicroRNA-10b pleiotropically regulates invasion, angiogenicity and apoptosis of tumor cells resembling mesenchymal subtype of glioblastoma multiforme. Cell Death Dis 3:e398. https://doi.org/10.1038/cddis.2012.134

75. Liu C, Sarkaria JN, Petell CA, Paraskevakou G, Zollman PJ, Schroeder M, Carlson B, Decker PA, Wu W, James CD et al (2007) Combination of measles virus virotherapy and radiation therapy has synergistic activity in the treatment of glioblastoma multiforme. Clin Cancer Res 13:7155-7165. https://doi.org/10.1158/1078-0432.Ccr-07-1306

76. Liu Q, Guan Y, Li Z, Wang Y, Liu Y, Cui R, Wang Y (2019) miR-504 suppresses mesenchymal phenotype of glioblastoma by directly targeting the FZD7-mediated Wnt-beta-catenin pathway. J Exp Clin Cancer Res 38:358. https://doi.org/10.1186/s13046-019-1370-1

77. Liu T, Ma W, Xu H, Huang M, Zhang D, He Z, Zhang L, Brem S, O'Rourke DM, Gong $Y$ et al (2018) PDGF-mediated mesenchymal transformation renders endothelial resistance to anti-VEGF treatment in glioblastoma. Nat Commun 9:3439. https://doi.org/10.1038/s41467-018-05982-z

78. Lobbous M, Bernstock JD, Coffee E, Friedman GK, Metrock LK, Chagoya G, Elsayed G, Nakano I, Hackney JR, Korf BR et al (2020) An update on neurofibromatosis type 1-associated gliomas. Cancers (Basel). https:// doi.org/10.3390/cancers12010114

79. Lu-Emerson C, Snuderl M, Kirkpatrick ND, Goveia J, Davidson C, Huang Y, Riedemann L, Taylor J, Ivy P, Duda DG et al (2013) Increase in tumorassociated macrophages after antiangiogenic therapy is associated with poor survival among patients with recurrent glioblastoma. Neuro Oncol 15:1079-1087. https://doi.org/10.1093/neuonc/not082

80. Lyons YA, Pradeep S, Wu SY, Haemmerle M, Hansen JM, Wagner MJ, Villar-Prados A, Nagaraja AS, Dood RL, Previs RA et al (2017) Macrophage depletion through colony stimulating factor 1 receptor pathway blockade overcomes adaptive resistance to anti-VEGF therapy. Oncotarget 8:96496-96505. https://doi.org/10.18632/oncotarget.20410

81. Ma H, Zhao C, Zhao Z, Hu L, Ye F, Wang H, Fang Z, Wu Y, Chen X (2020) Specific glioblastoma multiforme prognostic-subtype distinctions based on DNA methylation patterns. Cancer Gene Ther 27:702-714 https://doi.org/10.1038/s41417-019-0142-6

82. Ma X, Yoshimoto K, Guan Y, Hata N, Mizoguchi M, Sagata N, Murata H, Kuga D, Amano T, Nakamizo A et al (2012) Associations between microRNA expression and mesenchymal marker gene expression in glioblastoma. Neuro Oncol 14:1153-1162. https://doi.org/10.1093/ neuonc/nos145

83. Mahmoudi K, Bouras A, Bozec D, Ivkov R, Hadjipanayis C (2018) Magnetic hyperthermia therapy for the treatment of glioblastoma: a review of the therapy's history, efficacy and application in humans. Int J Hyperthermia 34:1316-1328. https://doi.org/10.1080/02656736.2018. 1430867

84. Maier-Hauff K, Ulrich F, Nestler D, Niehoff H, Wust P, Thiesen B, Orawa $H$, Budach V, Jordan A (2011) Efficacy and safety of intratumoral thermotherapy using magnetic iron-oxide nanoparticles combined with external beam radiotherapy on patients with recurrent glioblastoma multiforme. J Neuro-Oncol 103:317-324. https://doi.org/10.1007/ s11060-010-0389-0

85. Majd N, de Groot J (2019) Challenges and strategies for successful clinical development of immune checkpoint inhibitors in glioblastoma. Expert Opin Pharmacother. https://doi.org/10.1080/14656566.2019. 1621840

86. Mao P, Joshi K, Li J, Kim SH, Li P, Santana-Santos L, Luthra S, Chandran UR, Benos PV, Smith L et al (2013) Mesenchymal glioma stem cells are maintained by activated glycolytic metabolism involving aldehyde dehydrogenase 1A3. Proc Natl Acad Sci USA 110:8644-8649. https:// doi.org/10.1073/pnas.1221478110

87. Marekova D, Turnovcova K, Sursal TH, Gandhi CD, Jendelova P, Jhanwar-Uniyal M (2020) Potential for treatment of glioblastoma: new aspects of superparamagnetic iron oxide nanoparticles. Anticancer Res 40:5989-5994. https://doi.org/10.21873/anticanres.14619

88. Masliantsev K, Karayan-Tapon L, Guichet PO (2021) Hippo signaling pathway in gliomas. Cells. https://doi.org/10.3390/cells10010184

89. Mikheeva SA, Mikheev AM, Petit A, Beyer R, Oxford RG, Khorasani L, Maxwell JP, Glackin CA, Wakimoto H, Gonzalez-Herrero I et al (2010) TWIST1 promotes invasion through mesenchymal change in human glioblastoma. Mol Cancer 9:194. https://doi.org/10.1186/ 1476-4598-9-194

90. Min C, Eddy SF, Sherr DH, Sonenshein GE (2008) NF-kappaB and epithelial to mesenchymal transition of cancer. J Cell Biochem 104:733-744. https://doi.org/10.1002/jcb.21695

91. Minata M, Audia A, Shi J, Lu S, Bernstock J, Pavlyukov MS, Das A, Kim SH, Shin YJ, Lee Y et al (2019) Phenotypic plasticity of invasive edge glioma stem-like cells in response to ionizing radiation. Cell Rep 26(18931905):e1897. https://doi.org/10.1016/j.celrep.2019.01.076

92. Monteiro AR, Hill R, Pilkington GJ, Madureira PA (2017) The role of hypoxia in glioblastoma invasion. Cells. https://doi.org/10.3390/cells 6040045

93. Moreno M, Pedrosa L, Pare L, Pineda E, Bejarano L, Martinez J, Balasubramaniyan V, Ezhilarasan R, Kallarackal N, Kim SH et al (2017) GPR56/ ADGRG1 inhibits mesenchymal differentiation and radioresistance in glioblastoma. Cell Rep 21:2183-2197. https://doi.org/10.1016/j.celrep. 2017.10.083

94. Morin A, Letouze E, Gimenez-Roqueplo AP, Favier J (2014) Oncometabolites-driven tumorigenesis: from genetics to targeted therapy. Int J Cancer 135:2237-2248. https://doi.org/10.1002/ijc.29080

95. Morris SL, Zhu P, Rao M, Martir M, Zhu JJ, Hsu S, Ballester LY, Day AL, Tandon N, Kim DH et al (2019) Gamma knife stereotactic radiosurgery in combination with bevacizumab for recurrent glioblastoma. World Neurosurg 127:e523-e533. https://doi.org/10.1016/j.wneu.2019.03.193

96. Nagarsheth N, Wicha MS, Zou W (2017) Chemokines in the cancer microenvironment and their relevance in cancer immunotherapy. Nat Rev Immunol 17:559-572. https://doi.org/10.1038/nri.2017.49

97. Nagashima T, Shigematsu N, Maruki R, Urano Y, Tanaka H, Shimaya A, Shimokawa T, Shibasaki M (2010) Discovery of novel forkhead box 01 inhibitors for treating type 2 diabetes: improvement of fasting glycemia 
in diabetic db/db mice. Mol Pharmacol 78:961-970. https://doi.org/10. $1124 / \mathrm{mol} .110 .065714$

98. Nakano I (2014) Proneural-mesenchymal transformation of glioma stem cells: do therapies cause evolution of target in glioblastoma? Future Oncol 10:1527-1530. https://doi.org/10.2217/fon.14.86

99. Nakashima K, Yanagisawa M, Arakawa H, Kimura N, Hisatsune T, Kawabata M, Miyazono K, Taga T (1999) Synergistic signaling in fetal brain by STAT3-Smad1 complex bridged by p300. Science 284:479-482. https:// doi.org/10.1126/science.284.5413.479

100. Neftel C, Laffy J, Filbin MG, Hara T, Shore ME, Rahme GJ, Richman AR, Silverbush D, Shaw ML, Hebert CM et al (2019) An integrative model of cellular states, plasticity, and genetics for glioblastoma. Cell 178(835849):e821. https://doi.org/10.1016/j.cell.2019.06.024

101. Niklasson M, Bergstrom T, Jarvius M, Sundstrom A, Nyberg F, Haglund C, Larsson R, Westermark B, Segerman B, Segerman A (2019) Mesenchymal transition and increased therapy resistance of glioblastoma cells is related to astrocyte reactivity. J Pathol. https://doi.org/10.1002/path. 5317

102. Nonoguchi N, Miyatake S, Fukumoto M, Furuse M, Hiramatsu R, Kawabata S, Kuroiwa T, Tsuji M, Fukumoto M, Ono K (2011) The distribution of vascular endothelial growth factor-producing cells in clinical radiation necrosis of the brain: pathological consideration of their potential roles. J Neuro-Oncol 105:423-431. https://doi.org/10.1007/ s11060-011-0610-9

103. Omuro A, DeAngelis LM (2013) Glioblastoma and other malignant gliomas: a clinical review. JAMA 310:1842-1850. https://doi.org/10.1001/ jama.2013.280319

104. Ozawa T, Riester M, Cheng Y-K, Huse Jason T, Squatrito M, Helmy K, Charles N, Michor F, Holland Eric C (2014) Most human non-GCIMP glioblastoma subtypes evolve from a common proneural-like precursor glioma. Cancer Cell 26:288-300. https://doi.org/10.1016/j.ccr.2014.06. 005

105. Paquin A, Barnabé-Heider F, Kageyama R, Miller FD (2005) CCAAT/ enhancer-binding protein phosphorylation biases cortical precursors to generate neurons rather than astrocytes in vivo. J Neurosci 25:1074710758. https://doi.org/10.1523/jneurosci.2662-05.2005

106. Park KJ, Kano H, Iyer A, Liu X, Niranjan A, Flickinger JC, Lieberman FS, Lunsford LD, Kondziolka D (2012) Salvage gamma knife stereotactic radiosurgery followed by bevacizumab for recurrent glioblastoma multiforme: a case-control study. J Neuro-Oncol 107:323-333. https:// doi.org/10.1007/s11060-011-0744-9

107. Park SJ, Smith CP, Wilbur RR, Cain CP, Kallu SR, Valasapalli S, Sahoo A, Guda MR, Tsung AJ, Velpula KK (2018) An overview of MCT1 and MCT4 in GBM: small molecule transporters with large implications. Am J Cancer Res 8:1967-1976

108. Patel AP, Tirosh I, Trombetta JJ, Shalek AK, Gillespie SM, Wakimoto H, Cahill DP, Nahed BV, Curry WT, Martuza RL et al (2014) Single-cell RNAseq highlights intratumoral heterogeneity in primary glioblastoma. Science 344:1396-1401. https://doi.org/10.1126/science.1254257

109. Patel U, Patel A, Cobb C, Benkers T, Vermeulen S (2014) The management of brain necrosis as a result of SRS treatment for intra-cranial tumors. Transl Cancer Res 3:373-382

110. Paunescu IA, Bardan R, Marcu A, Nitusca D, Dema A, Negru S, Balacescu O, Balacescu L, Cumpanas A, Sirbu IO et al (2019) Biomarker potential of plasma MicroRNA-150-5p in prostate cancer. Medicina (Kaunas). https://doi.org/10.3390/medicina55090564

111. Pavlides S, Whitaker-Menezes D, Castello-Cros R, Flomenberg N, Witkiewicz AK, Frank PG, Casimiro MC, Wang C, Fortina P, Addya S et al (2009) The reverse Warburg effect: aerobic glycolysis in cancer associated fibroblasts and the tumor stroma. Cell Cycle 8:3984-4001. https://doi. org/10.4161/cc.8.23.10238

112. Pavlova NN, Thompson CB (2016) The emerging hallmarks of cancer metabolism. Cell Metab 23:27-47. https://doi.org/10.1016/j.cmet.2015. 12.006

113. Perrin SL, Samuel MS, Koszyca B, Brown MP, Ebert LM, Oksdath M, Gomez GA (2019) Glioblastoma heterogeneity and the tumour microenvironment: implications for preclinical research and development of new treatments. Biochem Soc Trans 47:625-638. https://doi.org/10. 1042/BST20180444

114. Phillips HS, Kharbanda S, Chen R, Forrest WF, Soriano RH, Wu TD, Misra A, Nigro JM, Colman H, Soroceanu L et al (2006) Molecular subclasses of high-grade glioma predict prognosis, delineate a pattern of disease progression, and resemble stages in neurogenesis. Cancer Cell 9:157-173. https://doi.org/10.1016/..ccr.2006.02.019

115. Piao Y, Liang J, Holmes L, Henry V, Sulman E, de Groot JF (2013) Acquired resistance to anti-VEGF therapy in glioblastoma is associated with a mesenchymal transition. Clin Cancer Res 19:4392-4403. https:// doi.org/10.1158/1078-0432.CCR-12-1557

116. Piao Y, Liang J, Holmes L, Zurita AJ, Henry V, Heymach JV, de Groot JF (2012) Glioblastoma resistance to anti-VEGF therapy is associated with myeloid cell infiltration, stem cell accumulation, and a mesenchymal phenotype. Neuro Oncol 14:1379-1392. https://doi.org/10.1093/ neuonc/nos158

117. Piovan E, Yu J, Tosello V, Herranz D, Ambesi-Impiombato A, Da Silva AC, Sanchez-Martin M, Perez-Garcia A, Rigo I, Castillo M et al (2013) Direct reversal of glucocorticoid resistance by AKT inhibition in acute lymphoblastic leukemia. Cancer Cell 24:766-776. https://doi.org/10.1016/j.ccr. 2013.10.022

118. Polonen $\mathrm{P}$, Jawahar Deen $\mathrm{A}$, Leinonen HM, Jyrkkanen HK, Kuosmanen $\mathrm{S}$, Mononen M, Jain A, Tuomainen T, Pasonen-Seppanen S, Hartikainen JM et al (2019) Nrf2 and SQSTM1/p62 jointly contribute to mesenchymal transition and invasion in glioblastoma. Oncogene. https://doi.org/10. 1038/s41388-019-0956-6

119. Poon CC, Sarkar S, Yong VW, Kelly JJP (2017) Glioblastoma-associated microglia and macrophages: targets for therapies to improve prognosis. Brain 140:1548-1560. https://doi.org/10.1093/brain/aww355

120. Prins RM, Soto H, Konkankit V, Odesa SK, Eskin A, Yong WH, Nelson SF, Liau LM (2011) Gene expression profile correlates with T-cell infiltration and relative survival in glioblastoma patients vaccinated with dendritic cell immunotherapy. Clin Cancer Res 17:1603-1615. https://doi.org/10. 1158/1078-0432.CCR-10-2563

121. Puchalski RB, Shah N, Miller J, Dalley R, Nomura SR, Yoon JG, Smith KA, Lankerovich M, Bertagnolli D, Bickley K et al (2018) An anatomic transcriptional atlas of human glioblastoma. Science 360:660-663. https:// doi.org/10.1126/science.aaf2666

122. Pyonteck SM, Akkari L, Schuhmacher AJ, Bowman RL, Sevenich L, Quail DF, Olson OC, Quick ML, Huse JT, Teijeiro V et al (2013) CSF-1R inhibition alters macrophage polarization and blocks glioma progression. Nat Med 19:1264-1272. https://doi.org/10.1038/nm.3337

123. Quail DF, Bowman RL, Akkari L, Quick ML, Schuhmacher AJ, Huse JT, Holland EC, Sutton JC, Joyce JA (2016) The tumor microenvironment underlies acquired resistance to CSF-1R inhibition in gliomas. Science 352:aad3018. https://doi.org/10.1126/science.aad3018

124. Rahman NIA, Abdul Murad NA, Mollah MM, Jamal R, Harun R (2017) NFIX as a master regulator for lung cancer progression. Front Pharmacol 8:540. https://doi.org/10.3389/fphar.2017.00540

125. Rajesh Y, Biswas A, Mandal M (2017) Glioma progression through the prism of heat shock protein mediated extracellular matrix remodeling and epithelial to mesenchymal transition. Exp Cell Res 359:299-311. https://doi.org/10.1016/j.yexcr.2017.08.032

126. Ray A, Manjila S, Hdeib AM, Radhakrishnan A, Nock CJ, Cohen ML, Sloan AE (2015) Extracranial metastasis of gliobastoma: three illustrative cases and current review of the molecular pathology and management strategies. Mol Clin Oncol 3:479-486. https://doi.org/10.3892/mco.2015. 494

127. Rivera LB, Bergers $G$ (2013) Location, location, location: macrophage positioning within tumors determines pro- or antitumor activity. Cancer Cell 24:687-689. https://doi.org/10.1016/j.ccr.2013.11.014

128. Rodriguez-Barrueco R, Yu J, Saucedo-Cuevas LP, Olivan M, Llobet-Navas D, Putcha P, Castro V, Murga-Penas EM, Collazo-Lorduy A, Castillo-Martin $M$ et al (2015) Inhibition of the autocrine IL-6-JAK2-STAT3-calprotectin axis as targeted therapy for HR-/HER2+ breast cancers. Genes Dev 29:1631-1648. https://doi.org/10.1101/gad.262642.115

129. Rong X, Huang B, Qiu S, Li X, He L, Peng Y (2016) Tumor-associated macrophages induce vasculogenic mimicry of glioblastoma multiforme through cyclooxygenase-2 activation. Oncotarget 7:83976-83986. https://doi.org/10.18632/oncotarget.6930

130. Rutledge WC, Kong J, Gao J, Gutman DA, Cooper LA, Appin C, Park Y, Scarpace L, Mikkelsen T, Cohen ML et al (2013) Tumor-infiltrating lymphocytes in glioblastoma are associated with specific genomic alterations and related to transcriptional class. Clin Cancer Res 19:4951-4960. https://doi.org/10.1158/1078-0432.CCR-13-0551 
131. Sa JK, Chang N, Lee HW, Cho HJ, Ceccarelli M, Cerulo L, Yin J, Kim SS, Caruso FP, Lee M et al (2020) Transcriptional regulatory networks of tumor-associated macrophages that drive malignancy in mesenchymal glioblastoma. Genome Biol 21:216. https://doi.org/10.1186/ s13059-020-02140-x

132. Saha D, Martuza RL, Rabkin SD (2017) Macrophage polarization contributes to glioblastoma eradication by combination immunovirotherapy and immune checkpoint blockade. Cancer Cell 32(253-267):e255. https://doi.org/10.1016/j.ccell.2017.07.006

133. Sandmann T, Bourgon R, Garcia J, Li C, Cloughesy T, Chinot OL, Wick W, Nishikawa R, Mason W, Henriksson R et al (2015) Patients with proneural glioblastoma may derive overall survival benefit from the addition of bevacizumab to first-line radiotherapy and temozolomide: retrospective analysis of the AVAglio trial. J Clin Oncol 33:2735-2744. https://doi. org/10.1200/jco.2015.61.5005

134. Schiffer D, Annovazzi L, Casalone C, Corona C, Mellai M (2018) Glioblastoma: microenvironment and niche concept. Cancers (Basel). https:// doi.org/10.3390/cancers11010005

135. Segerman A, Niklasson M, Haglund C, Bergstrom T, Jarvius M, Xie Y, Westermark A, Sonmez D, Hermansson A, Kastemar M et al (2016) Clonal variation in drug and radiation response among gliomainitiating cells is linked to proneural-mesenchymal transition. Cell Rep 17:2994-3009. https://doi.org/10.1016/j.celrep.2016.11.056

136. Shah AH, Semonche A, Eichberg DG, Borowy V, Luther E, Sarkiss CA Morell A, Mahavadi AK, Ivan ME, Komotar RJ (2020) The role of laser interstitial thermal therapy in surgical neuro-oncology: series of 100 consecutive patients. Neurosurgery 87:266-275. https://doi.org/10. 1093/neuros/nyz424

137. Shen Y, Grisdale CJ, Islam SA, Bose P, Lever J, Zhao EY, Grinshtein N, Ma Y, Mungall AJ, Moore RA et al (2019) Comprehensive genomic profiling of glioblastoma tumors, BTICs, and xenografts reveals stability and adaptation to growth environments. Proc Natl Acad Sci USA 116:19098-19108. https://doi.org/10.1073/pnas.1813495116

138. Shime H, Yabu M, Akazawa T, Kodama K, Matsumoto M, Seya T, Inoue N (2008) Tumor-secreted lactic acid promotes IL-23/IL-17 proinflammatory pathway. J Immunol 180:7175-7183. https://doi.org/10.4049/ jimmunol.180.11.7175

139. Sikdar S, Datta S (2017) A novel statistical approach for identification of the master regulator transcription factor. BMC Bioinform 18:79. https:// doi.org/10.1186/s12859-017-1499-x

140. Skandalakis GP, Rivera DR, Rizea CD, Bouras A, Jesu Raj JG, Bozec D, Hadjipanayis CG (2020) Hyperthermia treatment advances for brain tumors. Int J Hyperth 37:3-19. https://doi.org/10.1080/02656736.2020.1772512

141. Sonveaux P, Copetti T, De Saedeleer CJ, Vegran F, Verrax J, Kennedy KM, Moon EJ, Dhup S, Danhier P, Frerart F et al (2012) Targeting the lactate transporter MCT1 in endothelial cells inhibits lactate-induced HIF-1 activation and tumor angiogenesis. PLoS ONE 7:e33418. https://doi. org/10.1371/journal.pone.0033418

142. Sottoriva A, Spiteri I, Piccirillo SG, Touloumis A, Collins VP, Marioni JC, Curtis C, Watts C, Tavare S (2013) Intratumor heterogeneity in human glioblastoma reflects cancer evolutionary dynamics. Proc Natl Acad Sci USA 110:4009-4014. https://doi.org/10.1073/pnas.1219747110

143. Stafford JH, Hirai T, Deng L, Chernikova SB, Urata K, West BL, Brown JM (2016) Colony stimulating factor 1 receptor inhibition delays recurrence of glioblastoma after radiation by altering myeloid cell recruitment and polarization. Neuro Oncol 18:797-806. https://doi.org/10.1093/neuonc/ nov 272

144. Steinestel K, Eder S, Schrader AJ, Steinestel J (2014) Clinical significance of epithelial-mesenchymal transition. Clin Transl Med 3:17. https://doi. org/10.1186/2001-1326-3-17

145. Stupp R, Mason WP, van den Bent MJ, Weller M, Fisher B, Taphoorn MJ, Belanger K, Brandes AA, Marosi C, Bogdahn U et al (2005) Radiotherapy plus concomitant and adjuvant temozolomide for glioblastoma. N Engl J Med 352:987-996. https://doi.org/10.1056/NEJMoa043330

146. Talasila KM, Rosland GV, Hagland HR, Eskilsson E, Flones IH, Fritah S, Azuaje F, Atai N, Harter PN, Mittelbronn M et al (2017) The angiogenic switch leads to a metabolic shift in human glioblastoma. Neuro Oncol 19:383-393. https://doi.org/10.1093/neuonc/now175

147. Tan Z, Xie N, Banerjee S, Cui H, Fu M, Thannickal VJ, Liu G (2015) The monocarboxylate transporter 4 is required for glycolytic reprogramming and inflammatory response in macrophages. J Biol Chem 290:46-55. https://doi.org/10.1074/jbc.M114.603589

148. Taniguchi K, Karin M (2018) NF-kappaB, inflammation, immunity and cancer: coming of age. Nat Rev Immunol 18:309-324. https://doi.org/ 10.1038/nri.2017.142

149. Thomas AA, Brennan CW, DeAngelis LM, Omuro AM (2014) Emerging therapies for glioblastoma. JAMA Neurol 71:1437-1444. https://doi.org/ 10.1001/jamaneurol.2014.1701

150. Timke C, Zieher H, Roth A, Hauser K, Lipson KE, Weber KJ, Debus J, Abdollahi A, Huber PE (2008) Combination of vascular endothelial growth factor receptor/platelet-derived growth factor receptor inhibition markedly improves radiation tumor therapy. Clin Cancer Res 14:2210-2219. https://doi.org/10.1158/1078-0432.CCR-07-1893

151. Urbanska K, Sokolowska J, Szmidt M, Sysa P (2014) Glioblastoma multiforme-an overview. Contemp Oncol (Pozn) 18:307-312. https://doi. org/10.5114/wo.2014.40559

152. van den Bossche WBL, Kleijn A, Teunissen CE, Voerman JSA, Teodosio C, Noske DP, van Dongen JJM, Dirven CMF, Lamfers MLM (2018) Oncolytic virotherapy in glioblastoma patients induces a tumor macrophage phenotypic shift leading to an altered glioblastoma microenvironment. Neuro Oncol 20:1494-1504. https://doi.org/10.1093/neuonc/noy082

153. Vatner RE, Formenti SC (2015) Myeloid-derived cells in tumors: effects of radiation. Semin Radiat Oncol 25:18-27. https://doi.org/10.1016/j. semradonc.2014.07.008

154. Vegran F, Boidot R, Michiels C, Sonveaux P, Feron O (2011) Lactate influx through the endothelial cell monocarboxylate transporter MCT1 supports an NF-kappaB/IL-8 pathway that drives tumor angiogenesis. Cancer Res 71:2550-2560. https://doi.org/10.1158/0008-5472.Can-10-2828

155. Verhaak RG, Hoadley KA, Purdom E, Wang V, Qi Y, Wilkerson MD, Miller CR, Ding L, Golub T, Mesirov JP et al (2010) Integrated genomic analysis identifies clinically relevant subtypes of glioblastoma characterized by abnormalities in PDGFRA, IDH1, EGFR, and NF1. Cancer Cell 17:98-110. https://doi.org/10.1016/j.ccr.2009.12.020

156. Vigneswaran K, Boyd NH, Oh SY, Lallani S, Boucher A, Neill SG, Olson JJ, Read RD (2020) YAP/TAZ transcriptional coactivators create therapeutic vulnerability to verteporfin in EGFR-mutant glioblastoma. Clin Cancer Res. https://doi.org/10.1158/1078-0432.CCR-20-0018

157. Wang D, Berglund AE, Kenchappa RS, MacAulay RJ, Mule JJ, Etame AB (2017) BIRC3 is a biomarker of mesenchymal habitat of glioblastoma, and a mediator of survival adaptation in hypoxia-driven glioblastoma habitats. Sci Rep 7:9350. https://doi.org/10.1038/s41598-017-09503-8

158. Wang J, Cazzato E, Ladewig E, Frattini V, Rosenbloom DI, Zairis S, Abate F, Liu Z, Elliott O, Shin YJ et al (2016) Clonal evolution of glioblastoma under therapy. Nat Genet 48:768-776. https://doi.org/10.1038/ng.3590

159. Wang M, Zhao J, Zhang L, Wei F, Lian Y, Wu Y, Gong Z, Zhang S, Zhou J, Cao K et al (2017) Role of tumor microenvironment in tumorigenesis. J Cancer 8:761-773. https://doi.org/10.7150/jca.17648

160. Wang Q, He Y, Kan W, Li F, Ji X, Wu X, Wang X, Zhang Y, Chen J (2019) microRNA-32-5p targets KLF2 to promote gastric cancer by activating PI3K/AKT signaling pathway. Am J Transl Res 11:4895-4908

161. Wang Q, Hu B, Hu X, Kim H, Squatrito M, Scarpace L, deCarvalho AC, Lyu S, Li P, Li Y et al (2017) Tumor evolution of glioma-intrinsic gene expression subtypes associates with immunological changes in the microenvironment. Cancer Cell 32:42-56.e46. https://doi.org/10.1016/j. ccell.2017.06.003

162. Wang SC, Yu CF, Hong JH, Tsai CS, Chiang CS (2013) Radiation therapyinduced tumor invasiveness is associated with SDF-1-regulated macrophage mobilization and vasculogenesis. PLoS ONE 8:e69182. https:// doi.org/10.1371/journal.pone.0069182

163. Weller M, Cloughesy T, Perry JR, Wick W (2013) Standards of care for treatment of recurrent glioblastoma-Are we there yet? Neuro Oncol 15:4-27. https://doi.org/10.1093/neuonc/nos273

164. Wick W, Platten M, Wick A, Hertenstein A, Radbruch A, Bendszus M, Winkler $F$ (2016) Current status and future directions of anti-angiogenic therapy for gliomas. Neuro Oncol 18:315-328. https://doi.org/10.1093/ neuonc/nov180

165. Wilde L, Roche M, Domingo-Vidal M, Tanson K, Philp N, Curry J, Martinez-Outschoorn U (2017) Metabolic coupling and the reverse Warburg effect in cancer: Implications for novel biomarker and anticancer agent development. Semin Oncol 44:198-203. https://doi.org/10. 1053/j.seminoncol.2017.10.004 
166. Wood MD, Reis GF, Reuss DE, Phillips JJ (2016) Protein analysis of glioblastoma primary and posttreatment pairs suggests a mesenchymal shift at recurrence. J Neuropathol Exp Neurol 75:925-935. https://doi. org/10.1093/jnen/nlw068

167. Xu X, Bao Z, Liu Y, Jiang K, Zhi T, Wang D, Fan L, Liu N, Ji J (2018) PBX3/ MEK/ERK1/2/LIN28/let-7b positive feedback loop enhances mesenchymal phenotype to promote glioblastoma migration and invasion. J Exp Clin Cancer Res 37:158. https://doi.org/10.1186/s13046-018-0841-0

168. Yachi K, Tsuda M, Kohsaka S, Wang L, Oda Y, Tanikawa S, Ohba Y, Tanaka $S$ (2018) miR-23a promotes invasion of glioblastoma via HOXD10-regulated glial-mesenchymal transition. Signal Transduct Target Ther 3:33. https://doi.org/10.1038/s41392-018-0033-6

169. Yamini B (2018) NF-kappaB, mesenchymal differentiation and glioblastoma. Cells. https://doi.org/10.3390/cells7090125

170. Yan D, Kowal J, Akkari L, Schuhmacher AJ, Huse JT, West BL, Joyce JA (2017) Inhibition of colony stimulating factor-1 receptor abrogates microenvironment-mediated therapeutic resistance in gliomas. Oncogene 36:6049-6058. https://doi.org/10.1038/onc.2017.261

171. Yang M, Soga T, Pollard PJ (2013) Oncometabolites: linking altered metabolism with cancer. J Clin Investig 123:3652-3658. https://doi.org/ $10.1172 / \mathrm{JCl} 67228$

172. Yang W, Wu PF, Ma JX, Liao MJ, Wang XH, Xu LS, Xu MH, Yi L (2019) Sortilin promotes glioblastoma invasion and mesenchymal transition through GSK-3beta/beta-catenin/twist pathway. Cell Death Dis 10:208. https://doi.org/10.1038/s41419-019-1449-9

173. Yee PP, Wei Y, Kim SY, Lu T, Chih SY, Lawson C, Tang M, Liu Z, Anderson B, Thamburaj K et al (2020) Neutrophil-induced ferroptosis promotes tumor necrosis in glioblastoma progression. Nat Commun 11:5424. https://doi.org/10.1038/s41467-020-19193-y

174. Yin J, Oh YT, Kim JY, Kim SS, Choi E, Kim TH, Hong JH, Chang N, Cho HJ, Sa JK et al (2017) Transglutaminase 2 inhibition reverses mesenchymal transdifferentiation of glioma stem cells by regulating C/EBPbeta signaling. Cancer Res 77:4973-4984. https://doi.org/10.1158/0008-5472. Can-17-0388

175. Yoritsune E, Furuse M, Kuwabara H, Miyata T, Nonoguchi N, Kawabata S, Hayasaki H, Kuroiwa T, Ono K, Shibayama Y et al (2014) Inflammation as well as angiogenesis may participate in the pathophysiology of brain radiation necrosis. J Radiat Res 55:803-811. https://doi.org/10.1093/jrr/ rru017

176. Young RM, Jamshidi A, Davis G, Sherman JH (2015) Current trends in the surgical management and treatment of adult glioblastoma. Ann Transl Med 3:121. https://doi.org/10.3978/j.issn.2305-5839.2015.05.10

177. Yuan J, Levitin HM, Frattini V, Bush EC, Boyett DM, Samanamud J, Ceccarelli M, Dovas A, Zanazzi G, Canoll P et al (2018) Single-cell transcriptome analysis of lineage diversity in high-grade glioma. Genome Med 10:57. https://doi.org/10.1186/s13073-018-0567-9

178. Zanotto-Filho A, Goncalves RM, Klafke K, de Souza PO, Dillenburg FC, Carro L, Gelain DP, Moreira JC (2017) Inflammatory landscape of human brain tumors reveals an NFkappaB dependent cytokine pathway associated with mesenchymal glioblastoma. Cancer Lett 390:176-187. https://doi.org/10.1016/j.canlet.2016.12.015
179. Zhang C, Han X, Xu X, Zhou Z, Chen X, Tang Y, Cheng J, Moazzam NF, Liu F, Xu J et al (2018) FoxM1 drives ADAM17/EGFR activation loop to promote mesenchymal transition in glioblastoma. Cell Death Dis 9:469. https://doi.org/10.1038/s41419-018-0482-4

180. Zhang H, Geng D, Gao J, Qi Y, Shi Y, Wang Y, Jiang Y, Zhang Y, Fu J, Dong $Y$ et al (2016) Expression and significance of Hippo/YAP signaling in glioma progression. Tumour Biol. https://doi.org/10.1007/ s13277-016-5318-1

181. Zhang M, Kleber S, Rohrich M, Timke C, Han N, Tuettenberg J, MartinVillalba A, Debus J, Peschke P, Wirkner U et al (2011) Blockade of TGFbeta signaling by the TGFbetaR-I kinase inhibitor LY2109761 enhances radiation response and prolongs survival in glioblastoma. Cancer Res 71:7155-7167. https://doi.org/10.1158/0008-5472.CAN-11-1212

182. Zhang Q, Liu F (2020) Advances and potential pitfalls of oncolytic viruses expressing immunomodulatory transgene therapy for malignant gliomas. Cell Death Dis 11:485. https://doi.org/10.1038/ s41419-020-2696-5

183. Zhang X, Ding K, Wang J, Li X, Zhao P (2019) Chemoresistance caused by the microenvironment of glioblastoma and the corresponding solutions. Biomed Pharmacother 109:39-46. https://doi.org/10.1016/j. biopha.2018.10.063

184. Zhang X, Wang X, Xu R, Ji J, Xu Y, Han M, Wei Y, Huang B, Chen A, Zhang $Q$ et al (2018) YM155 decreases radiation-induced invasion and reverses epithelial-mesenchymal transition by targeting STAT3 in glioblastoma. J Transl Med 16:79. https://doi.org/10.1186/s12967-018-1451-5

185. Zhang YH, Li Z, Zeng T, Pan X, Chen L, Liu D, Li H, Huang T, Cai YD (2020) Distinguishing glioblastoma subtypes by methylation signatures. Front Genet 11:604336. https://doi.org/10.3389/fgene.2020.604336

186. Zhong J, Paul A, Kellie SJ, O’Neill GM (2010) Mesenchymal migration as a therapeutic target in glioblastoma. J Oncol 2010:430142. https://doi. org/10.1155/2010/430142

187. Zhou YC, Liu JY, Li J, Zhang J, Xu YQ, Zhang HW, Qiu LB, Ding GR, Su XM, Mei $S$ et al (2011) lonizing radiation promotes migration and invasion of cancer cells through transforming growth factor-beta-mediated epithelial-mesenchymal transition. Int J Radiat Oncol Biol Phys 81:1530-1537. https://doi.org/10.1016/j.jirobp.2011.06.1956

\section{Publisher's Note}

Springer Nature remains neutral with regard to jurisdictional claims in published maps and institutional affiliations.

Ready to submit your research? Choose BMC and benefit from

- fast, convenient online submission

- thorough peer review by experienced researchers in your field

- rapid publication on acceptance

- support for research data, including large and complex data types

- gold Open Access which fosters wider collaboration and increased citations

- maximum visibility for your research: over 100M website views per year

At BMC, research is always in progress.

Learn more biomedcentral.com/submissions 